\title{
Chemicals, Metals, and Pesticide Pits . Waste Unit Low Induction Number Electromagnetic Survey $(\mathrm{U})$
}

Westinghouse Savannah River Company

Savannah River Site

Aiken, SC 29808

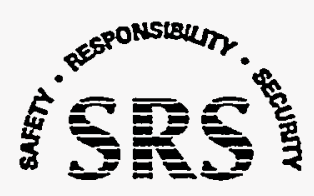

Prepared for the U.S. Department of Energy under Contract No. DE-AC09-89SR1 8035

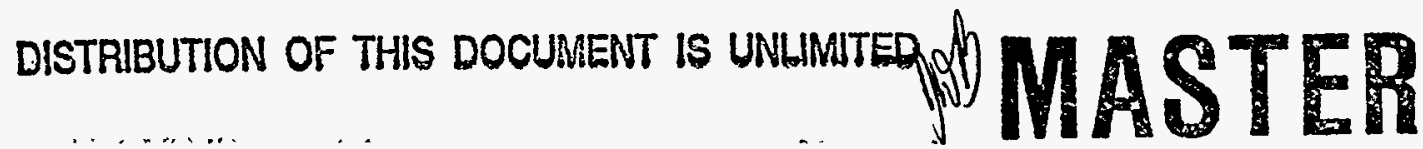




Disclaimer
This report was prepared as an account of work sponsored by an agency
of the United States Government. Neither the United States Government
nor any agency thereof, nor any of their employees, makes any warranty,
express or implied, or assumes any legal liability or responsibility for the
accuracy, completeness, or usefulness of any information, apparatus,
product, or process disclosed, or represents that its use would not
infringe privately owned rights. Reference herein to any specific com-
mercial product, process, or service by trade name, trademark, manufac-
turer, or otherwise does not necessarily constitute or imply its
endorsement, recommendation, or favoring by the United States Govern-
ment or any agency thereof. The views and opinions of authors
expressed herein do not necessarily state or reflect those of the United
.States Government or any agency thereof.

\section{Published in cooperation with WSRC Management Services} Department Publications Group.

Technical Editor: Charlie Tope 


\section{DISCLAIMERR}

Portions of this document may be illegible in electronic image products. Images are produced from the best available original document. 
WSRC-TR-95-0231

Publication Date: June 1995

\section{Chemicals, Metals, and Pesticide Pits Waste Unit Low Induction Number Electromagnetic Survey $(\mathrm{U})$}

R. J. Cumbest and Dave Mohon

Site Geotechnical Services

Prepared for the U.S. Department of Energy under Contract No. DE-AC09-89SR18035 
This page intentionally left blank. 


\section{Contents}

Executive Summary ...................................................................... 1

Introduction and Scope ..................................................... 3

Electromagnetic Survey Concepts ............................................. 3

The EM Technique ....................................................................3

The Low Induction Number Constraint ...................................................4

Description of Survey Site............................................................ 5

Electromagnetic Survey ............................................................ 7

Survey and Analytical Techniques .......................................... 7

Electromagnetic Data Set................................................... 7

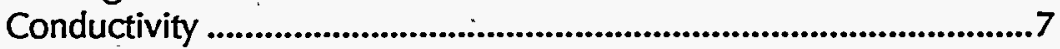

In-Phase Component......................................................................8

Discussion and Conclusions.......................................9 9

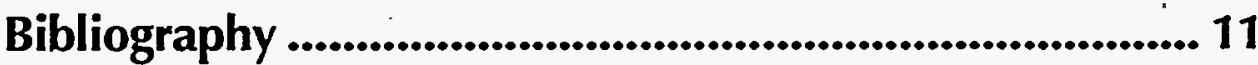

Appendix A-Surveyed Electromagnetic

Survey Station Locations ............................. 29

Appendix B-Instrument QA..................................... 39

\section{List of Figures}

Figure 1. Location of the Chemicals, Metals, and Pesticide Pits Waste Unit at SRS

Figure 2. A simple electromagnetic transmitter circuit

Figure 3. Coupling of an electromagnetic transmitting circuit to a nearby receiver circuit by mutual inductance through an alternating magnetic field $(\mathbf{H})$

Figure 4. Mutual inductive coupling between equivalent circuits representing an electromagnetic transmitter, a receiver, and conductive earth

Figure 5. Vector representation of the phase relationships between the primary $\left(\boldsymbol{H}_{\mathrm{p}}\right)$ and secondary $\left(\boldsymbol{H}_{\mathrm{s}}\right)$ magnetic fields for systems coupled by mutual inductance (after Telford and others, 1978) 
Figure 6. Orientations of transmitter (Tx) and receiver $(\mathrm{R} x)$ circuits relative to uniform halfspace of constant conductivity $(\sigma)$. Circuit orientations are described by a vector oriented along the circuit coil axis with magnitude dependent on the current in the circuit and circuit diameter. The circuits are separated in space by distance (s).

Figure 7. Relative response for horizontal $\left(\phi_{\mathrm{H}}(\mathrm{z})\right)$ and vertically $\left(\phi_{\mathrm{v}}(\mathrm{z})\right)$ oriented dipoles from a thin layer at normalized depth $\mathrm{z}$ (depth/dipole separation). Also shown, the cumulative response for a vertical dipole $\left(R_{v}(z)\right)$ for all material below the normalized depth (z).

Figure 8. Planimetric map of the Chemicals, Metals, and Pesticide Pit Waste Unit

Figure 9. Electromagnetic survey station locations in Savannah River Site coordinate system reference

Figure 10. Color contoured electromagnetic survey vertical dipole conductivity data for dipole common axis oriented north-south

Figure 11. Color contoured electromagnetic survey vertical dipole conductivity data for dipole common axis oriented east-west

Figure 12. Color contoured conductivity difference between the north-south and eastwest orientations

Figure 13. Color contoured vertical dipole in-phase component for north-south dipole common axis orientation

Figure 14. Color contoured vertical dipole in-phase component for east-west dipole common axis orientation

Figure 15. Color contoured geometric mean for both orientations of in-phase data with suspected areas of buried metallic objects outlined 


\section{Executive Summary}

An electromagnetic survey was conducted at the Chemicals, Metals, and Pesticide Waste Unit to identify any buried metallic objects that may be present in the materials used to fill and cover the pits after removal of pit debris. The survey was conducted with a Geonics EM-31 Terrain Conductivity Meter along north - south oriented traverses with 5-ft station intervals to produce a 5-ft by 5-ft square grid node pattern. Both conductivity and in-phase components were measured at each station for vertical dipole orientation with the common axis of the dipoles in the north - south and east - west orientatịns.

The conductivity data clearly show elevated conductivities $(2.1$ to $7.0 \mathrm{mS} / \mathrm{m})$ associated with the material over the pits, as compared with the surrounding area that is characterized by lower conductivities ( 1 to $2 \mathrm{mS} / \mathrm{m}$ ). This is probably the result of the higher clay content of the fill material relative to the surrounding area, which has a higher sand to clay ratio and the presence of a plastic cover beneath the fill that has probably trapped water.

Many metal objects are present in the survey area including manhole covers, monitoring well heads, metal signs, drain culverts, abandoned wells, and HP waste unit marker balls. All of these exhibit associated conductivity and in-phase anomalies of various magnitude. In addition to these anomalies that can be definitely associated with surface sources, conductivity and in-phase anomalies are also present with no obvious surface source. These anomalies are probably indicative of subsurface buried metallic objects. A high concentration of these objects appears to be present in the southwest comer of the survey area. 
This page intentionally left blank. 


\section{Introduction and Scope}

The Chemical, Metals, and Pesticide Pits Waste Unit is located north of $L$ Area on SRS (Figure 1). This waste unit originally consisted of seven unlined pits used for disposal of various wastes. The pits were arranged in two rows on top of a small hill and were 10 to $15 \mathrm{ft}$ wide, 10 to $15 \mathrm{ft}$ deep, and 45 to $70 \mathrm{ft}$ long. In 1984 the pits were excavated, backfilled, and capped with a berm underlain by plastic.

To assess the possibility of buried metallic debris in the area around the capped trenches, an electromagnetic survey was conducted in August and September 1994 by the Site Geotechnical Services Department at the request of the Environmental Restoration Department. In particular, the occurrence of fluorescent lamp ballasts were the primary concern, in that several of these objects can be found at various locations around the trench cap.

To assess the applicability of a magnetic survey, a test was conducted over one of the exposed ballasts. It was determined that the anomalies generated by these objects was insufficient to make magnetic survey techniques feasible. Due to these results and the fact that the ballasts contain a large amount of nonferrous metal, it was decided that an electromagnetic technique would be more applicable.

\section{Electromagnetic Survey Concepts}

\section{The EM Technique}

Electromagnetic geophysical survey techniques are based primarily on the sensitivity of electromagnetic fields to nearby conductors. This sensitivity is manifested by changes in the amplitude and phase of an electromagnetic signal generated in the presence of a conductor (i.e. the earth or a buried metallic object). In practice this technique is employed to determine the conductivity (or inversely the resistivity) of the earth near the signal source (transmitter), or the presence of extremely good conductors such as metallic objects. These effects are detected by a sensor or antenna (receiver) placed some distance from the transmitter. The main advantage of the electromagnetic technique is that the transmitter and receiver devices can be made extremely portable; thus electromagnetic surveys can be aquired more efficiently than with other techniques for determining earth conductivity.

In principal, an electromagnetic transmitter can be characterized by the simple circuit illustrated in Figure 2. The components of this circuit consist of an alternating current source (ac) that produces a time varying current $\left(I_{V}\right)$ in the transmitting circuit. This current is limited by the resistance of the circuit $\left(R_{\mathcal{V}}\right)$, which is constant with time, and by the fact that the alternating electric current in the circuit induces a corresponding alternating electromagnietic field in the surrounding space. The effects of producing this electromagnetic field are characterized by the self inductance of the circuit $\left(L_{v}\right)$. The real effect of the inductance on the circuit can be thought of as a time-varying resistance in the circuit. The important point is that the transmitting circuit will produce an alternating electromagnetic field in surrounding space, with a specific amplitude, frequency, and phase that is determined by the characteristics of the various circuit components described above.

Since the transmitting circuit produces a time-varying magnetic field in surrounding space (primary field, $\mathbf{H}_{\mathrm{p}}$ ) it will couple to other circuits in this space. That is, the alternating magnetic field produced by the transmitting circuit will induce a current to flow in nearby circuits that are intersected by the magnetic fiux lines. This induced current in nearby circuits will also cause these circuits to produce a magnetic field in nearby space by self induction (secondary field, $\mathbf{H}_{\mathbf{s}}$ ) which in turn also affects the transmitter circuit. This coupling effect between the two circuits is called mutual inductance. The circuit that has the current induced by the transmitting circuit can also be characterized by its resistance $\left(R_{2}\right)$ and self inductance $\left(L_{2}\right)$ as shown in Figure 3. The main difference being that the altemating current (ac) source in the nontransmitting circuit is the alternating magnetic field produced by the transmitter rather than an internal circuit component (ac). The alternating current in the nontransmitter circuit will be of the same frequency as the transmitter, but will differ in both amplitude and phase depending on the values of $R_{a}$ and $L_{a}$.

Since the earth can be considered a conductor, it can also be described by a simple circuit coupled by mutual inductance to the electromagnetic field produced by the transmitter, and its resulting current flow can also be characterized by the simple circuit described above. In its most fundamental form the electromagnetic survey technique can be described by the utilization of the mutual inductance of the three circuits shown in Figure 4. A transmitter produces an electromagnetic field (primary field, $H_{p}$ ) that is coupled by mutual inductance to the earth, which because it is conductive, produces a secondary magnetic field $\left(H_{s}\right)$ that differs in both amplitude and phase from the primary field $\left(\mathrm{H}_{\mathrm{p}}\right)$. A third nearby circuit is coupled to both the transmitter and the earth by mutual inductance and therefore senses both the primary and secondary magnetic fields. Since the primary field is known, 
the secondary field produced by the earth can.be determined from analysis of the current induced in the antenna circuit.

The relationships discussed above are illustrated in Figure 5 , which shows a vector representation of the primary field produced by the transmitter $\left(\mathrm{H}_{\mathrm{p}}\right)$ and the secondary field produced by the conductor (i.e. earth or metal object, $\mathbf{H}_{\mathrm{s}}$ ), which differs from $\mathbf{H}_{\mathrm{p}}$ in amplitude and phase $(\alpha+\pi / 2)$ depending on the specific properties of the conductor. The field sensed by the antenna will be the resultant of $\mathbf{H}_{\mathrm{p}}$ and $H_{s}$, or $H_{r}$ Also, as shown in Figure 5 , the components of the secondary field $\left(\mathbf{H}_{\mathrm{s}}\right)$ are both in phase with the primary field (i.e. $H_{s} \sin \phi$ ), and the component 90 degrees out of phase with the primary field (i.e. $\mathrm{H}_{3} \cos \phi$ ) can be resolved. These components are termed the in-phase component and out-phase or quadrature component, respectively.

As stated above, the angle $\alpha+\pi / 2$ between the primary $\left(\mathbf{H}_{\mathrm{p}}\right)$ and secondary field $\left(\mathrm{H}_{\mathrm{s}}\right)$ is a function of the properties of the conductor. That is, for very good conductors $\alpha$ approaches $\pi / 2$ and the secondary field $\left(\mathrm{H}_{\mathrm{s}}\right)$ is 180 degrees out of phase with the primary field, resulting in a relatively small value for the quadrature component and a relatively larger magnitude for the in-phase component. For poor conductors $\alpha$ approaches 0 and the secondary field lags the primary field by 90 degrees, which results in a relatively small in-phase component and a relatively large value for the quadrature component. Based on this type of analysis it is apparent that the in-phase component is more sensitive to very good conductors, such as metal objects, than the quadrature phase, and that comparison of the in-phase and quadrature phase can be used to obtain information about the quality of the conductor in terms of its conductivity.

In reality the transmitter and antenna circuits are physical objects. That is, they consist of coils of wire that can be described by a vector in space aligned along the axis of the coil, whose magnitude depends on the diameter of the coil and the coil current. The coils are separated in space by some physical distance (s). Electromagnetic surveys are typically performed in either of two coil orientations (Figure 6). The axis of the coil can be oriented perpendicular to the surface of the earth (vertical dipole configuration) or parallel to the surface of the earth (horizontal dipole configuration). For a homogeneous halfspace (i.e. homogenous earth) the expressions for the ratios of the primary $\left(\mathrm{H}_{\mathrm{p}}\right)$ and secondary $\left(\mathrm{H}_{\mathrm{s}}\right)$ fields are given by McNeill (1980) as :

$$
\left(\frac{H_{s}}{H_{p}}\right)_{V}=\frac{2}{(\gamma s)^{2}}\left\{9-\left[9+9 \gamma s+\dot{4}(\gamma \dot{s})^{2}+(\gamma s)^{3}\right] e^{-\gamma s}\right\}
$$

$$
\left(\frac{H_{s}}{H_{p}}\right)_{H}=2\left\{1-\frac{3}{(\gamma s)^{2}}+\left[3+3 \gamma s+(\gamma s)^{2}\right] \frac{e^{-\gamma s}}{(\gamma s)^{2}}\right\}
$$

where $\gamma=\sqrt{i \omega \mu_{0} \sigma}$

$$
\omega=2 \pi f
$$

$f=$ frequency of the alternating electromagnetic field $(\mathrm{Hz})$

$\mu_{0}=$ permeability of free space

$s=$ the intercoil spacing

As can be readily' seen, the above expressions are complicated functions of frequency $(f)$, conductivity $(\sigma)$, and spacing between the transmitter and antenna, which makes the generalized interpretation of electromagnetic geophysical survey data complicated. However, there are some simplifying principals that may be utilized to extract useful information from electromagnetic survey data, in spite of the complicated relationship expressed in the above equations. For a halfspace of uniform conductivity $(\sigma)$, the attenuation of electromagnetic energy as a function of depth is dependent on the frequency of the alternating electromagnetic field ( $f$ ), given by the expression (McNeill, 1980):

$\delta=\sqrt{\frac{2}{\omega \mu_{0} \sigma}}=\frac{\sqrt{2 i}}{\gamma}$

where $\delta$ is termed the "skin depth", and is the distance in the halfspace that results in the attenuation of the amplitude of the electromagnetic wave by a factor of $1 / \mathrm{e}$. Based on this relationship it can be seen that for a halfspace of given conductivity, that lower frequencies will penetrate deeper into the halfspace before significant attenuation occurs than can higher frequency electromagnetic fields. The utility of the skin depth effect is that the depth of investigation of an electromagnetic survey may be controlled, in part, by the frequency of the electromagnetic field selected for the survey.

\section{The Low Induction Number Constraint}

Incorporating the intercoil spacing into the skin depth equation results in the following expression:

$$
\dot{\gamma} s=\sqrt{2} i \frac{s}{\delta}
$$

which highlights the quantity $s / \delta$ (ratio of intercoil spacing to skin depth), which is defined as the induction number (B). This relationship is significant because for values of $B$ 
much less than unity (i.e. $y<<1$ ) the complicated expressions for the ratios of the primary and secondary fields expressed in equations (1) and (2) are greatly simplified to:

$$
\left(\frac{H_{s}}{H_{p}}\right)_{V} \cong\left(\frac{H_{s}}{H_{p}}\right)_{H} \cong \frac{i B^{2}}{2} \cong \frac{i \omega \mu_{o} \sigma s^{2}}{4}
$$

For small B, that is low induction number, with constant frequency and intercoil spacing, the ratio of the primary to secondary fields for both the vertical and horizontal dipole conditions is linearly proportional to the conductivity, and the phase of the secondary field leads the primary by 90 degrees. To effectively achieve the low induction number condition $(B<1)$ the intercoil spacing is set to be much less than the skin depth $(s<<\delta)$ and the frequency of the electromagnetic field is set so that the following condition is satisfied:

$$
\omega=\frac{2}{\mu_{0} \sigma s^{2}}
$$

(McNeill, 1980). This choice of parameters allows the apparent conductivity to be defined by:

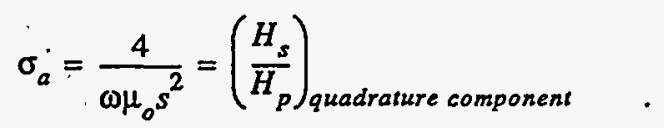

As the ground conductivity increases the approximations stated above become invalid, so that for a given intercoil spacing and operating frequency the linear relationship stated above breaks down.

In addition to the simplification in interpretation allowed by the low induction number condition, the fact that current flow in a uniform halfspace or horizontally stratified earth is horizontal means that for the low induction number condition the response measured at the surface of the earth for a layered model can be calculated from the sum of the response of 'each layer. This response will be a function of the depth of the layer and its conductivity. The relative contributions for a thin layer for both the horizontal $\left(\phi_{\mathrm{H}}(\mathrm{z})\right)$ and vertical dipole $\left(\phi_{\mathrm{v}}(\mathrm{z})\right)$ configurations are given by (McNeill, 1980):

$$
\phi_{V}(z)=\frac{4 z}{\left(4 z^{2}+1\right)^{3 / 2}}
$$

$\phi_{H}(z)=2-\frac{4 z}{\left(4 z^{2}+1\right)^{1 / 2}}$

where $\mathrm{z}$ is the normalized depth, defined as the depth divided by the intercoil spacing (s). The relative contribu- tion for material below a certain normalized depth $\left(R_{v}(z)\right.$ and $R_{\mathrm{H}}(\mathrm{z})$ ) may also be determined by integration of the above equations as:

$$
\begin{aligned}
& R_{V}(z)=\frac{1}{\left(4 z^{2}+1\right)^{1 / 2}} \\
& R_{H}(z)=\left(4 z^{2}+1\right)^{1 / 2}-2 z
\end{aligned}
$$

These relationships are illustrated in Figure 7.

\section{Description of Survey Site}

The Chemicals, Metals, and Pesticide Pits Waste Unit occurs as a grassy, cleared area surrounded by pine forest on a small hill. The fill over the waste unit is a raised rectangular berm surrounded by a shallow ditch. The berm and immediately surrounding area is a grassy field, clear of other vegetation. The remainder of the survey area contains clumps of small pines and brush interspersed with other areas that are relatively clear.

A planimetric map of the waste unit is shown in Figure 8. The comers of the berm are marked by HP orange waste unit marker balls. Several manholes penetrate the berm in the locations of the original trenches. These manholes consist of vertical concrete access holes covered by cast iron manhole covers. Also several metal signs and marker posts occur on the edge of the berm. In addition to these features, hydrologic monitoring well heads and abandoned well casings are present in several areas. In some places metal objects can be found on the ground surface, including a fallen metal sign and a culvert that runs under an access road. 
This page intentionally left blank. 


\section{Electromagnetic Survey}

\section{Survey and Analytical Techniques}

Due to the small size of lamp ballasts and the relatively large area to be covered by the survey (approximately 250 $\mathrm{ft}$ by $500 \mathrm{ft}$ ) fairly good location control was necessary so that any metallic objects located during the survey could be relocated and removed. Prior to acquiring the electromagnetic survey data, survey markers were located at 5-ft intervals along lines oriented east-west, and spaced $50 \mathrm{ft}$ apart to cover the area of interest. The locations of these surveyed stations are illustrated in Figure 9 in terms of the Savannah River Site coordinate system and the coórdinates given in Appendix $A$, along with corresponding magnetic survey grid node coordinates. During the course of the electromagnetic survey, a cord marked at 5-ft intervals was stretched between the 50-ft lines, and the electromagnetic data acquired along traverses oriented perperidicular to the surveyed lines. This technique allowed relatively good control in keeping the station marker cord straight, and was necessary in order to maintain location control due to the relatively thick vegetation in areas surrounding the berm. This produced a survey grid defined by 5 -ft by 5 -ft-square survey grid nodes.

The electromagnetic data were collected with a Geonics Model EM-31 Terrain Conductivity Meter equipped with an automatic data logger. This instrument employs an operating frequency of $9.8 \mathrm{kHz}$ with an intercoil spacing of $12 \mathrm{ft}$ ( 3.66 meters), which allows operation in the lowinduction-number mode for halfspace conductivites typical of the earth. Both quadrature (conductivity in millisiemens per meter $(\mathrm{mS} / \mathrm{m})$ ) and in-phase (in parts per thousand of the ratio of the secondary to primary magnetic fields) components were measured in the vertical-dipole mode at orientations both parallel and perpendicular to the traverse directions at each survey station. Before each measurement the instrument was allowed to settle down for 3 to 5 seconds. This set of measurements produced four data points for each station; the in-phase and quadrature components for the parallel direction, and the inphase and quadrature components for the perpendicular direction.

The manufacturer quotes a measurement accuracy of $5 \pm \%$ at $20 \mathrm{mS} / \mathrm{m}$, and noise levels of $0.1 \mathrm{mS} / \mathrm{m}$ and $0.03 \mathrm{ppt}$. In order to evaluate the precision of the instrument ten measurements of each value, made approximately 10 seconds apart, were made at a single station (grid node 0,0 ) on two successive days. The results of these measurements are tabulated in Appendix B. Standard deviations for the ten measurements of conductivity range between 0.05 and $0.12 \mathrm{mS} / \mathrm{m}$, and for the in-phase component between 0.019 . and $0.044 \mathrm{ppt}$, which is generally consistent with the values quoted from the manufacturer. However, the mean values for the conductivity show considerable drift from day to day, with consistently higher values on the second day for both orientations. Similar effects are present in the in-phase data although not as extreme. This same behavior was noted at irregular intervals during the conduct of the survey, and seemed to be correlated to temperature changes during the day. This behavior is probably a characteristic of this instrument in that the operator's manual mentions that mechanical vibration can cause zeroing errors.

To account for instrumental drift, the instrument was calibrated at a common point (grid node 0,0 ) at the beginning of each day and at periodic intervals during the day as the survey progressed. To constrain the effects due to the drift as much as possible, at the end of the survey the stations at the ends of each traverse line were remeasured after the instrument had been recalibrated in the early morning, when it was cool. This process took approximately 10 minutes so that no time was allowed for significant instrument drift to occur. In addition, this was accomplished as a closed survey loop so that any drift could be accounted for. Using these data the measurements along each survey line were corrected for drift by linear interpolation between the endpoints.

The data were downloaded from the data logger through a RS-232 port to an IBM PC Model 70. After downloading, the data were sorted and assigned coordinates with DAT31 software provided by Geonics. Further data display and processing, including gridding and contouring were accomplished with software provided by GEOSOFT Inc, Gridding of the data was accomplished with BIGRID, which is specifically designed to grid line data and enhance trends.

\section{Electromagnetic Data Set}

\section{Conductivity}

The conductivity data set for both the north-south and the east-west dipole orientations are shown in Figures 10 and 11. Most of the survey area surrounding the berm and the waste unit, as defined by the HP orange waste unit marker balls, shows conductivities ranging from 1 to $2 \mathrm{mS} / \mathrm{m}$. Conductivities measured for the berm over the waste unit are higher than the surrounding area, with values ranging from 2.1 to $7.0 \mathrm{mS} / \mathrm{m}$. In both of these areas a north-south corrugation can be seen in the data for both the east-west 
and north-south orientations. In addition to these broad conductivity trends, the data show prominent electromagnetic anomalies that exhibit negative conductivity values (physically not possible) associated with all of the metal objects seen on the surface, such as the manhole covers, the monitoring well heads, metal signs, and HP waste unit marker balls. The negative conductivities result from the highly conductive metal objects, which violate the basic assumptions of the low induction number operating condition and causes highly nonlinear behavior of the instrument response. However, the presence of these negative values can provide diagnostic help in locating metallic material. Anomalies are also present in the location of a metal drain culvert that runs under the access road to the site. Several other anomalies that exhibit negative conductivity values are evident in the conductivity data in the western and southwestern corner of the survey area.

Figure 12 shows the difference between the conductivity values for the north-south and east-west orientations. The data presented in this fashion enhances anisotropic conductivity features, or features smaller than the scale of the antenna separation. The conductivity anomaly from the berm is no longer present in the conductivity difference display, since it is several times the size of the antenna separation and of a uniform isotropic conductivity structure. However, the anomalies associated with the metal objects on the surface, in addition to those seen in the western part of the area, are highlighted.

\section{In-Phase Component}

The data for the in-phase component; for both the northsouth and east-west orientations are illustrated as color contour diagrams in Figures 13 and 14. These data in general show the same features as the conductivity data, with the exception that the anomaly associated with the berm is not present. The majority of the survey area is characterized by background values ranging from -0.2 to $+0.1 \mathrm{ppt}$. Both positive and negative in-phase anomalies are associated with all the large metal objects that can be seen on the surface of the survey area. In addition to these anomalies that can be easily identified, several smaller anomalies occur in the survey area. Several of these anomalies are concentrated in the southwest comer of the survey area. 


\section{Discussion and Conclusions}

The electromagnetic survey data for the Chemicals, Metals, and Pesticide Waste Unit over most of the survey area surrounding the fill berm show conductivities ranging from 1 to $2 \mathrm{mS} / \mathrm{m}$. The area over the berm reveals conductivities significantly higher than the surrounding area, with . conductivities from 2.1 to $7.0 \mathrm{mS} / \mathrm{m}$. Both areas show inphase components ranging from -0.3 to $+0.2 \mathrm{ppt}$. The conductivity differences exhibited between the berm and surrounding area is consistent with the composition of the soil types of the two areas. The fill material probably contains a high percentage of clay relative to the surrounding area, which is dominated by a higher sand/clay ratio, resulting in higher conductivities measured over the berm. This is probably compounded by the presence of trapped water above the plastic liner. The very low in-phase components exhibited by both of these areas in general indicated that there are no very broad expanses of highly conductive material. The background areas in both the conductivity and in-phase data also show north-south oriented corrugations. These corrugations are strongest in the north-south data set, and this is partially due to the anisotropy caused by the dipole orientation. However, the presence of corrugation in the east-west orientations indicates that most of this effect can be attributed to unresolved instrument drift associated with each traverse line.

The larger metal objects that can be seen at the surface of the survey site all have significant conductivity and inphase anomalies associated with them. These include the manhole covers, metal signs, drain culvert, and monitoring well heads. Small anomalies also occur associated with the HP waste unit marker balls and abandoned wells.

The other anomalies that occur are unexplained by metallic material that can easily be identified on the surface, and probably represent buried metal objects. A large concentration of these anomalies occurs in the southwest comer of the waste unit. Outlined areas showing anomalies in the geometric mean for both orientations of in-phase data of suspected buried metallic objects are shown in Figure 15.

The electromagnetic survey identified several large conductivity and in-phase anomalies in the survey area. Most of these anomalies can be definitely associated with metal objects readily identified on the surface. However, several smaller, isolated anomalies occur that may represent buried metallic objects. Several of these anomalies are concentrated in the southwest corner of the survey area. 
This page intentionally left blank: 


\section{Bibliography}

McNeill, J. D., 1980, Electromagnetic terrain conductivity measurement at low induction numbers, Technical note TN-6. Geonics Limited, Ontario Canada.

Telford, W. M., L. P. Geldart, R.E. Sheriff, and D. A. Keys, 1978, Applied Geophysics, Cambridge University

Press, p 860. 
This page intentionally left blank: 


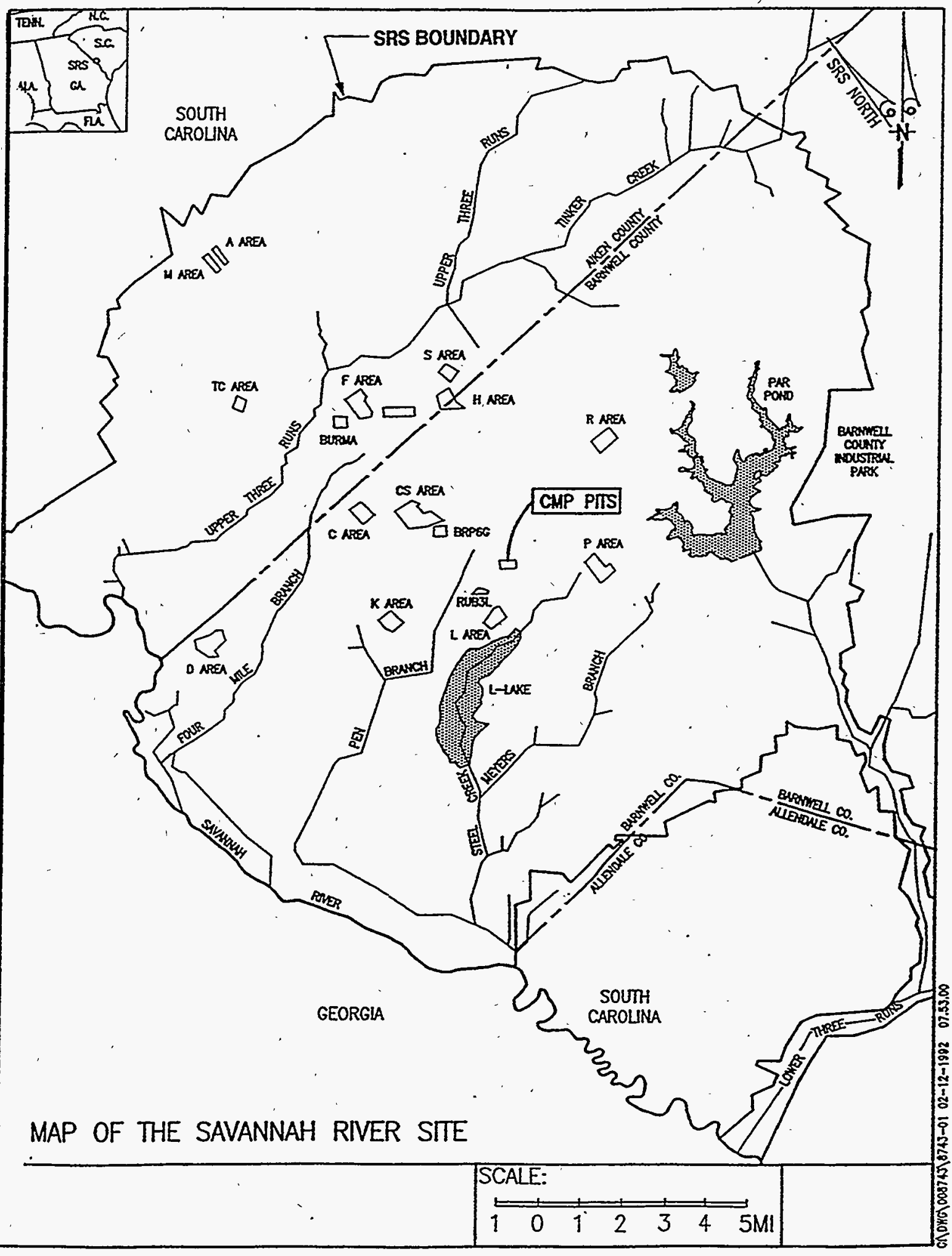

Figure 1. Location of the Chemicals, Metals, and Pesticide Pits Waste Unit at SRS 


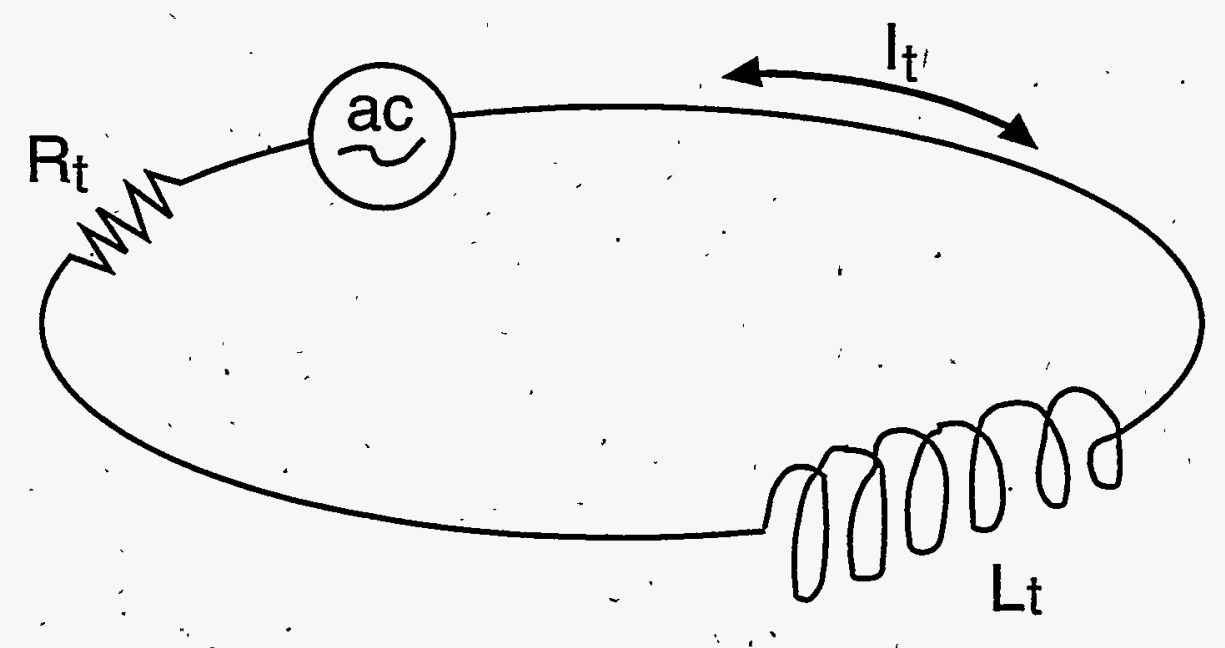

Figure 2. A simple electromagnetic transmitter circuit

95X02274.01.All 


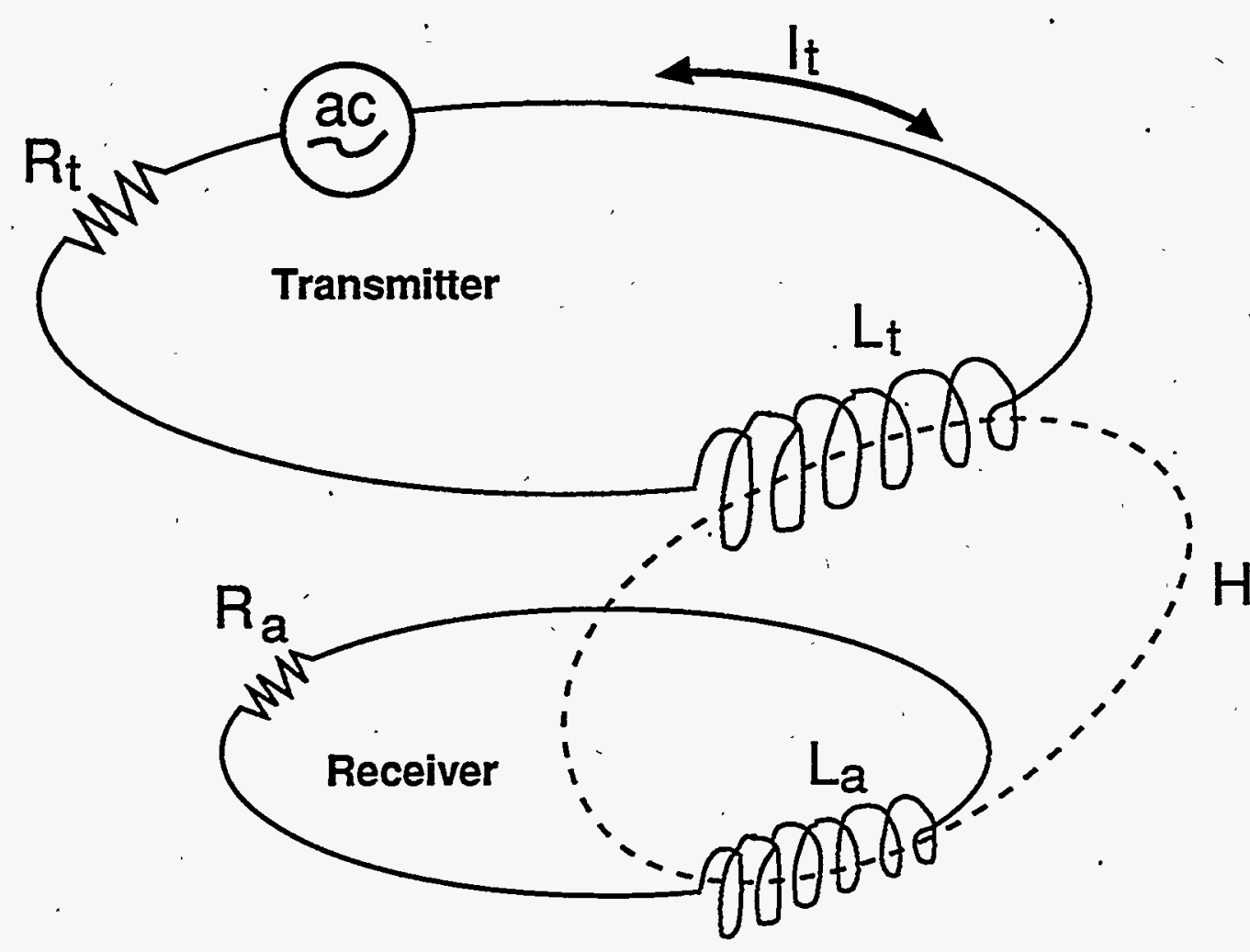

Figure 3. Coupling of an electromagnetic transmitting circuit to a nearby receiver circuit by mutual inductance through an alternating magnetic field $(\mathrm{H})$

95X02274.02.All 


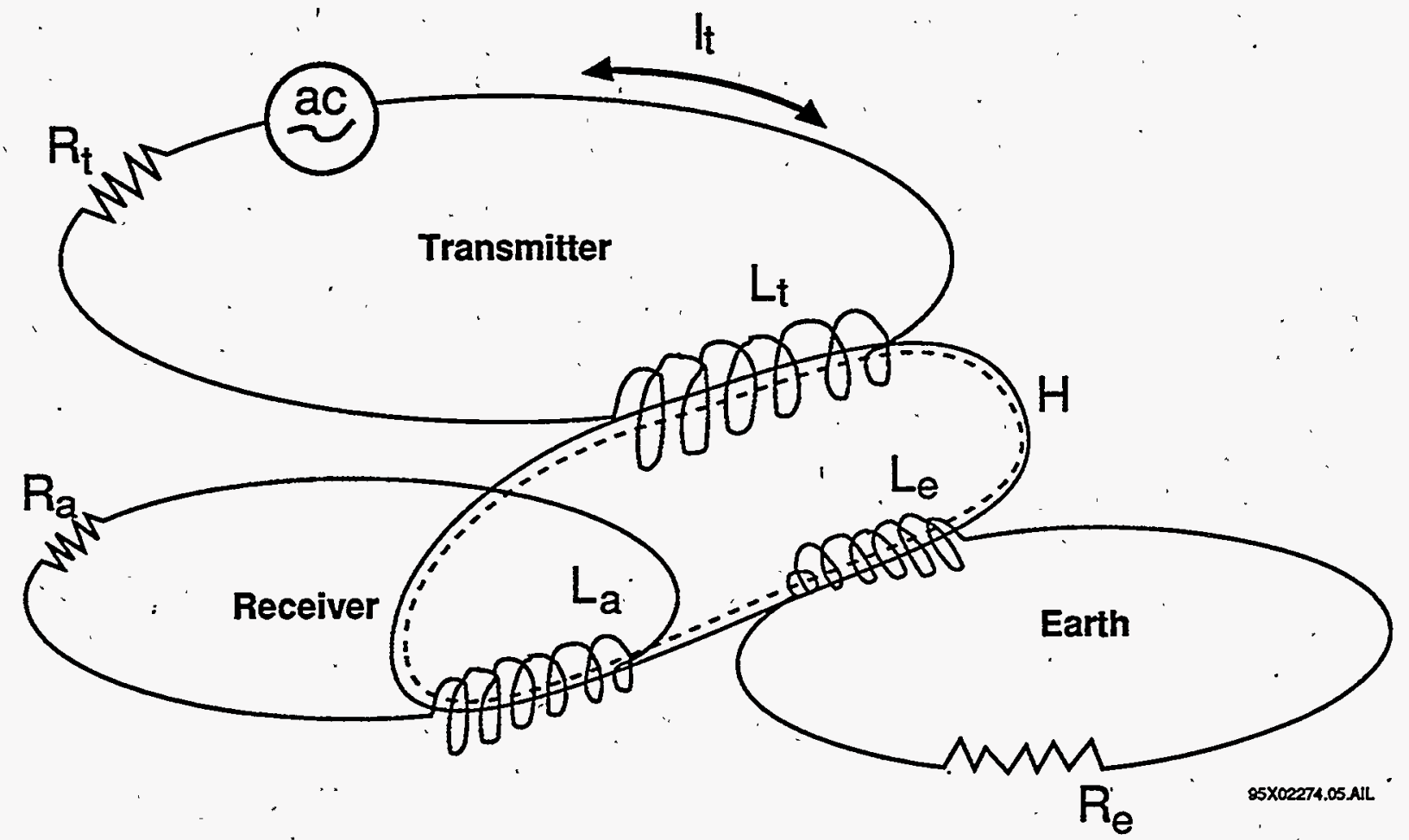

Figure 4. Mutual inductive coupling between equivalent circuits representing an electromagnetic transmitter, a receiver, and conductive earth 


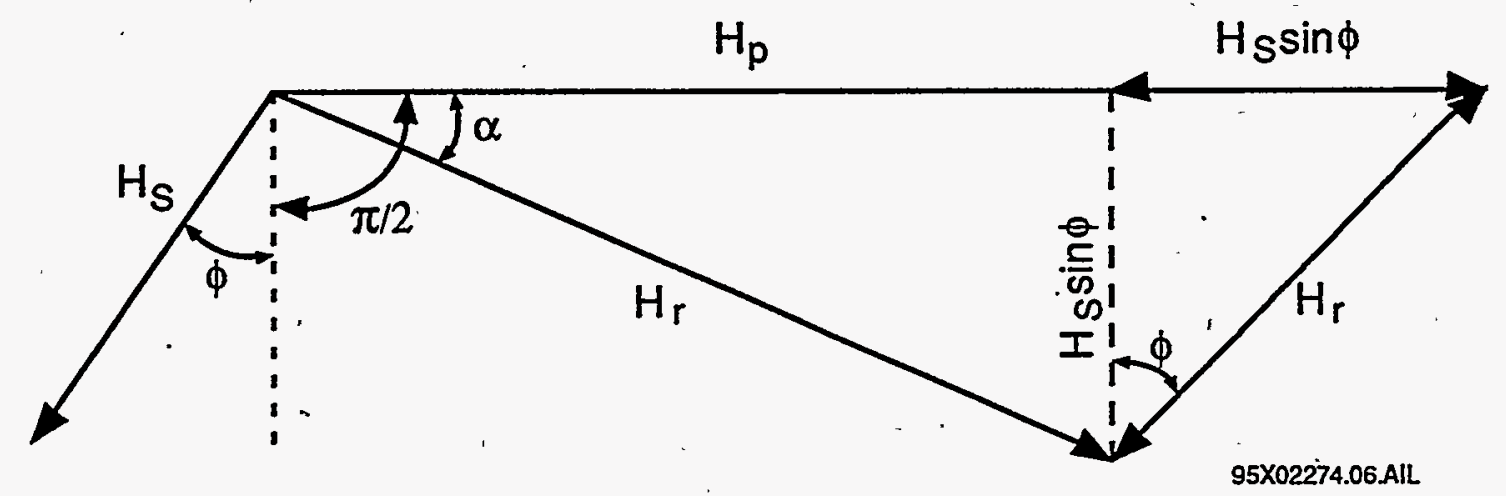

Figure 5. Vector representation of the phase relationships between the primary $\left(H_{p}\right)$ and secondary $\left(H_{s}\right)$ 'magnetic fields for systems coupled by mutual inductance (after Telford and others, 1978) 


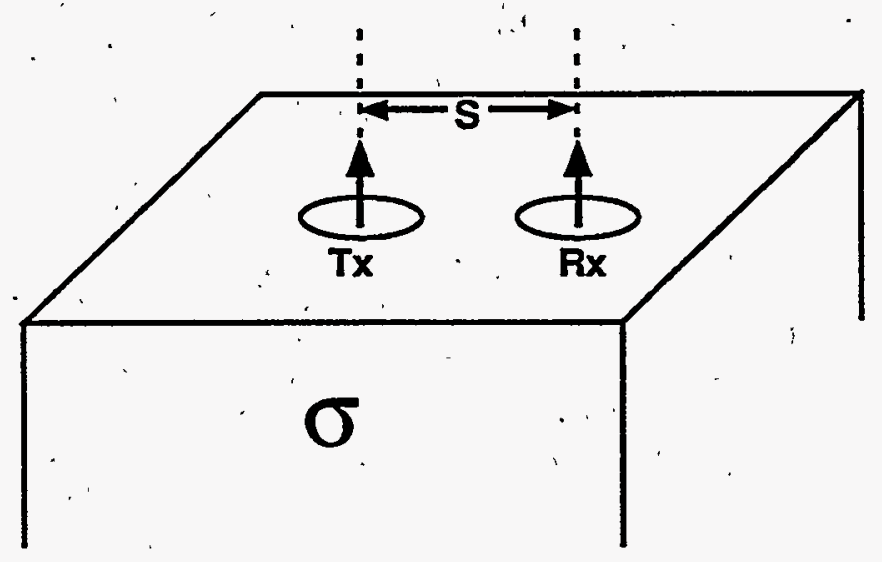

Vertical Dipole Configuration

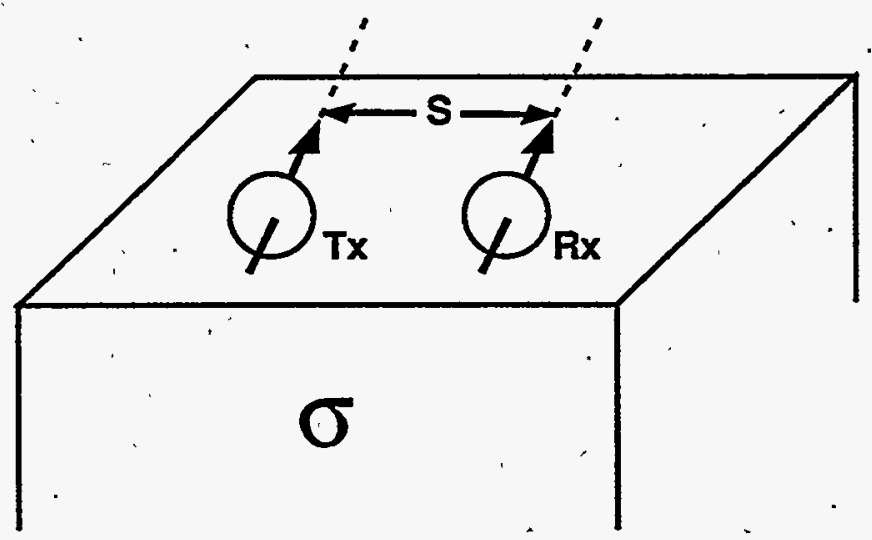

Horizontal Dipole Configuration

Figure 6. Orientations of transmitter $(T x)$ and receiver $(R x)$ circuits relative to uniform halfspace of constant conductivity $(\sigma)$. Circuit orientations are described by a vector oriented along the circuit coil axis with magnitude dependent on the current in the circuit and circuit diameter. The circuits are separated in space by distance (s). 

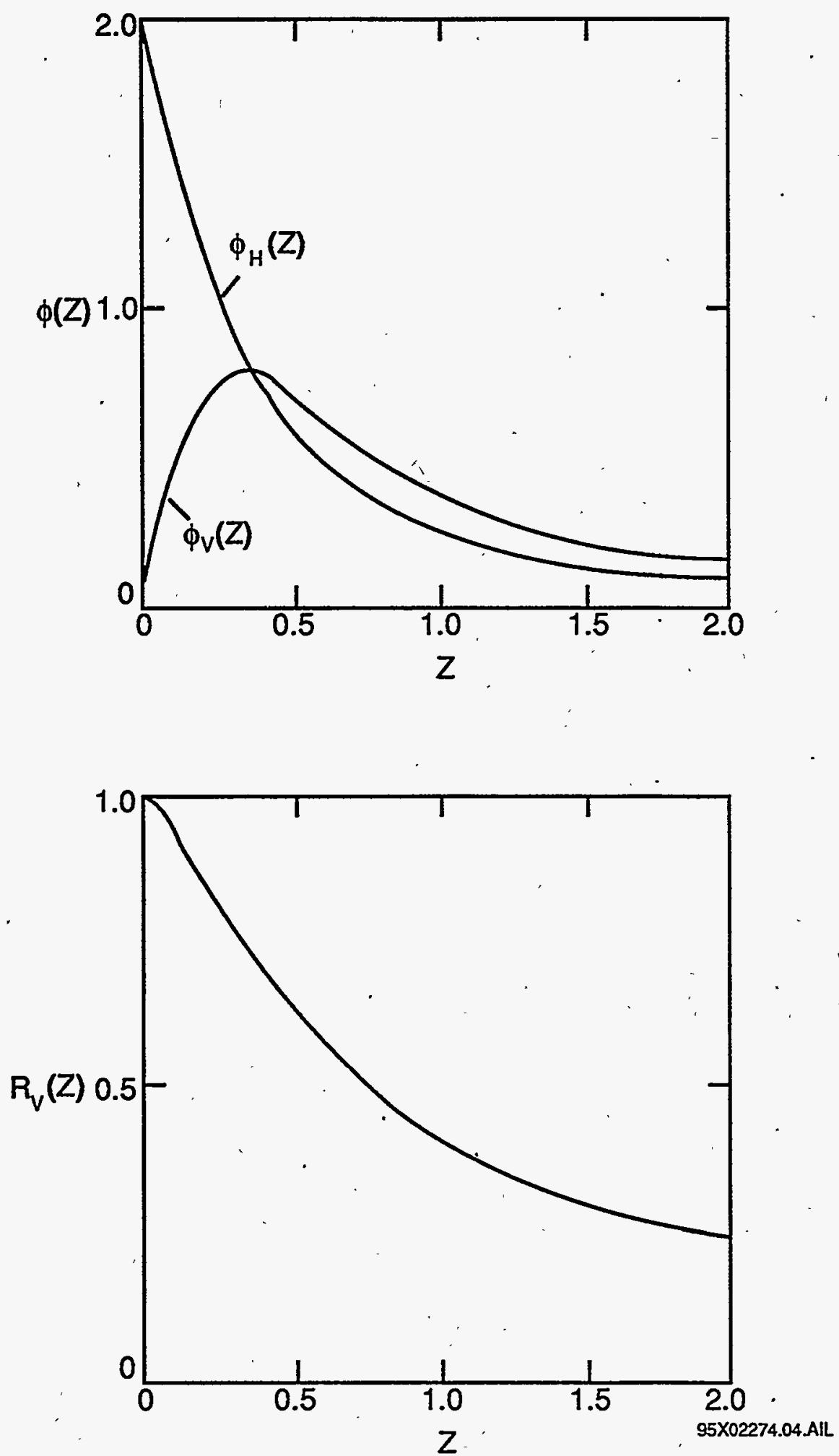

Figure 7. Relative response for horizontal $\left(\phi_{H}(Z)\right)$ and vertically $\left(\phi_{V}(Z)\right)$ oriented dipoles from a thin layer at, normalized depth $Z$ (depth/dipole separation). Also shown, the cumulative response for a vertical dipole $\left(R_{v}(Z)\right)$ for all material below the normalized depth (Z) (adapted from McNeill, 1980) 


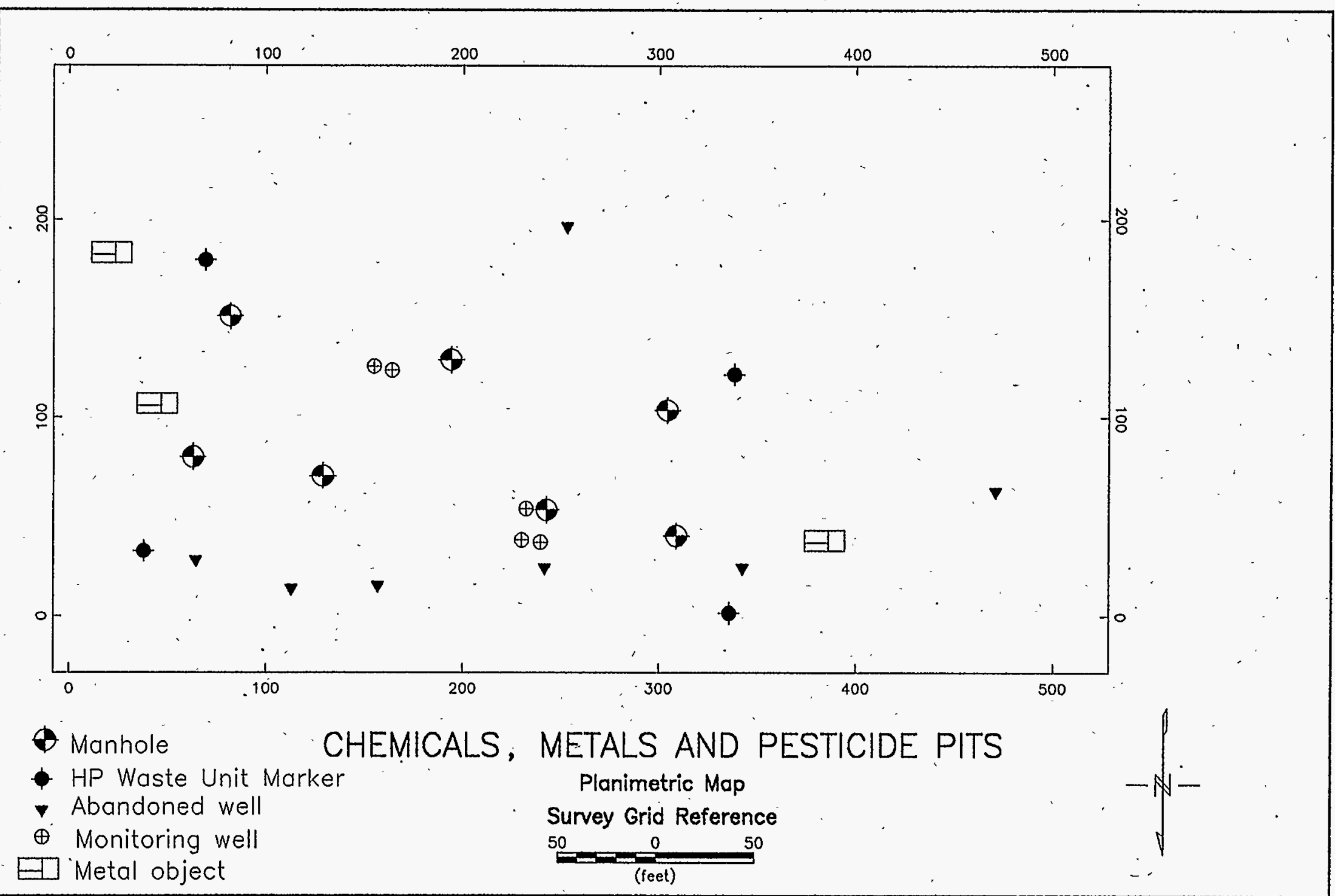

Figure 8. Planimetric map of the Chemicals, Metals, and Pesticide Pit Waste Unit 


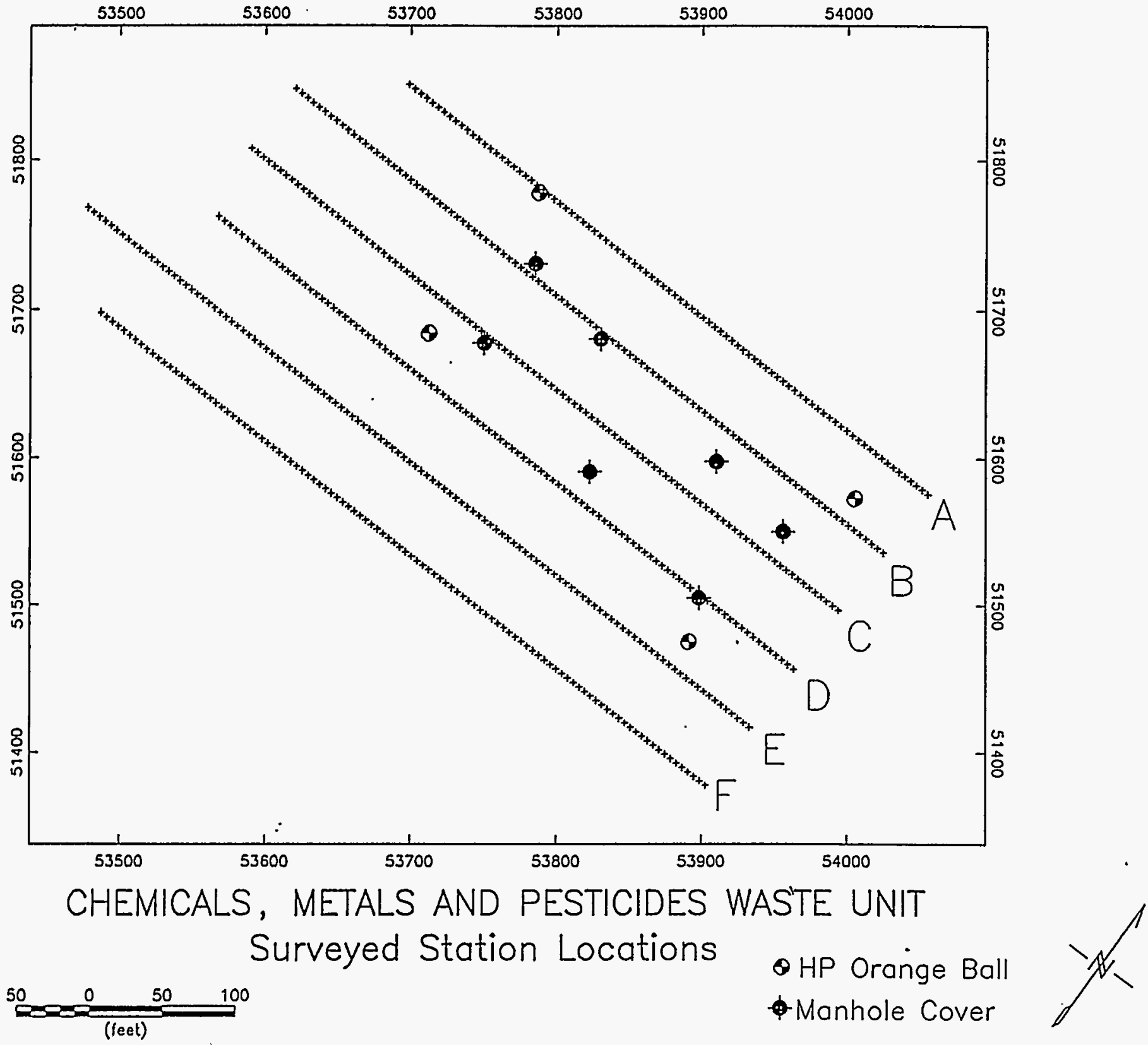

Figure 9. Electromagnetic survey station locations in Savannah River Site coordinate system reference 


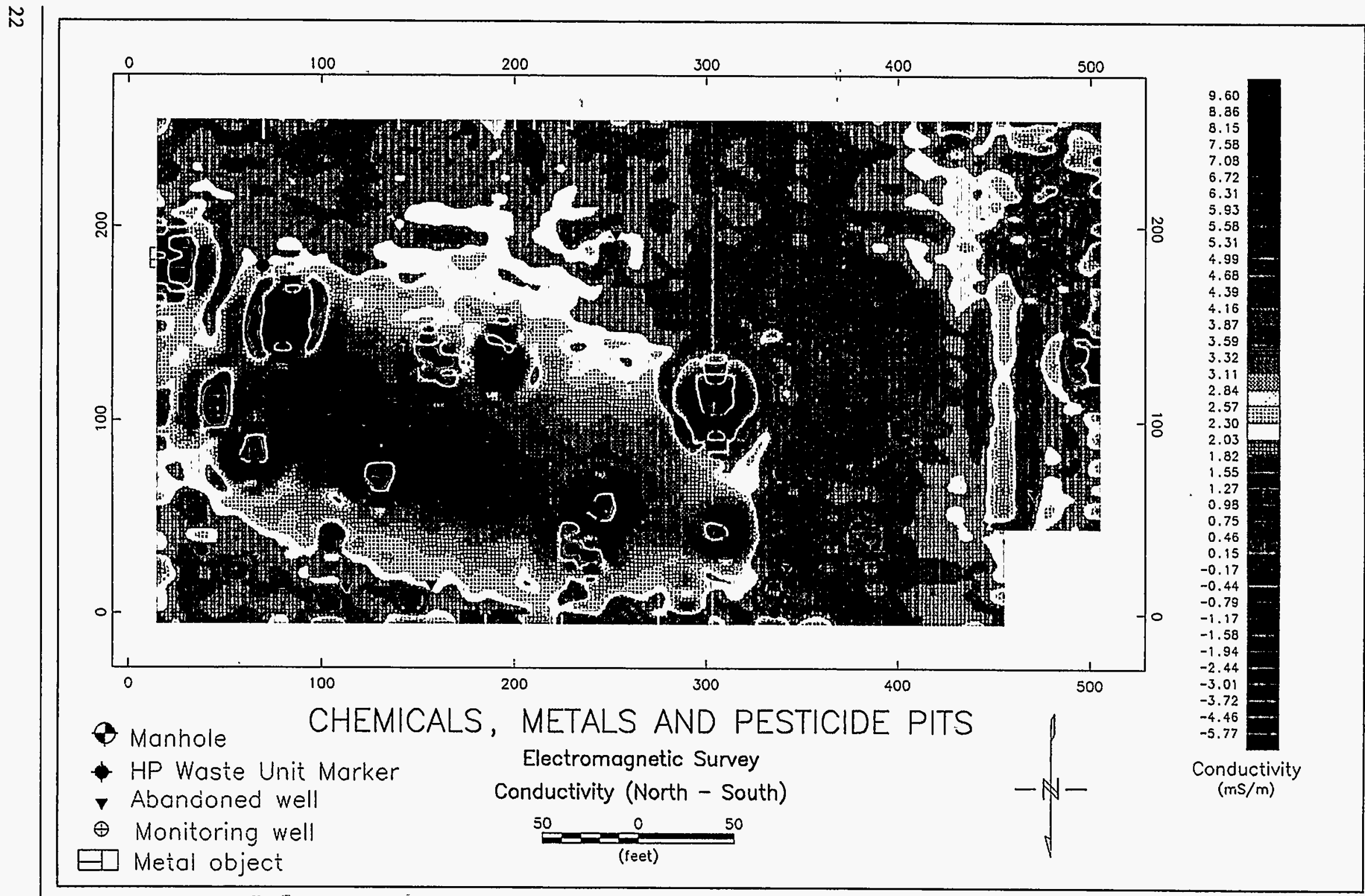

Figure 10. Color contoured electromagnetic survey vertical dipole conductivity data for dipole common axis oriented north-south 


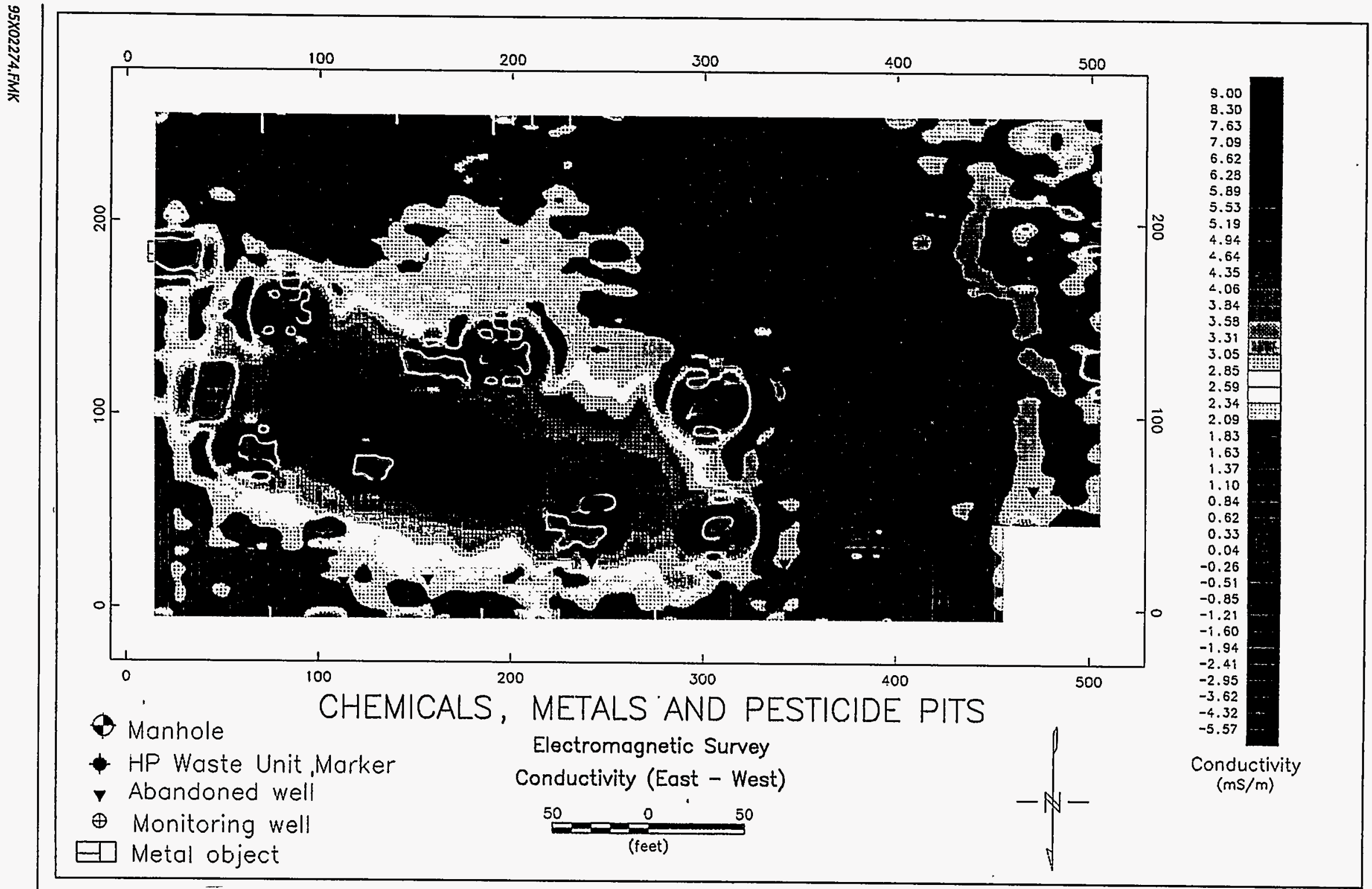

Figure 11. Color contoured electromagnetic survey vertical dipole conductivity data for dipole common axis oriented east-west 


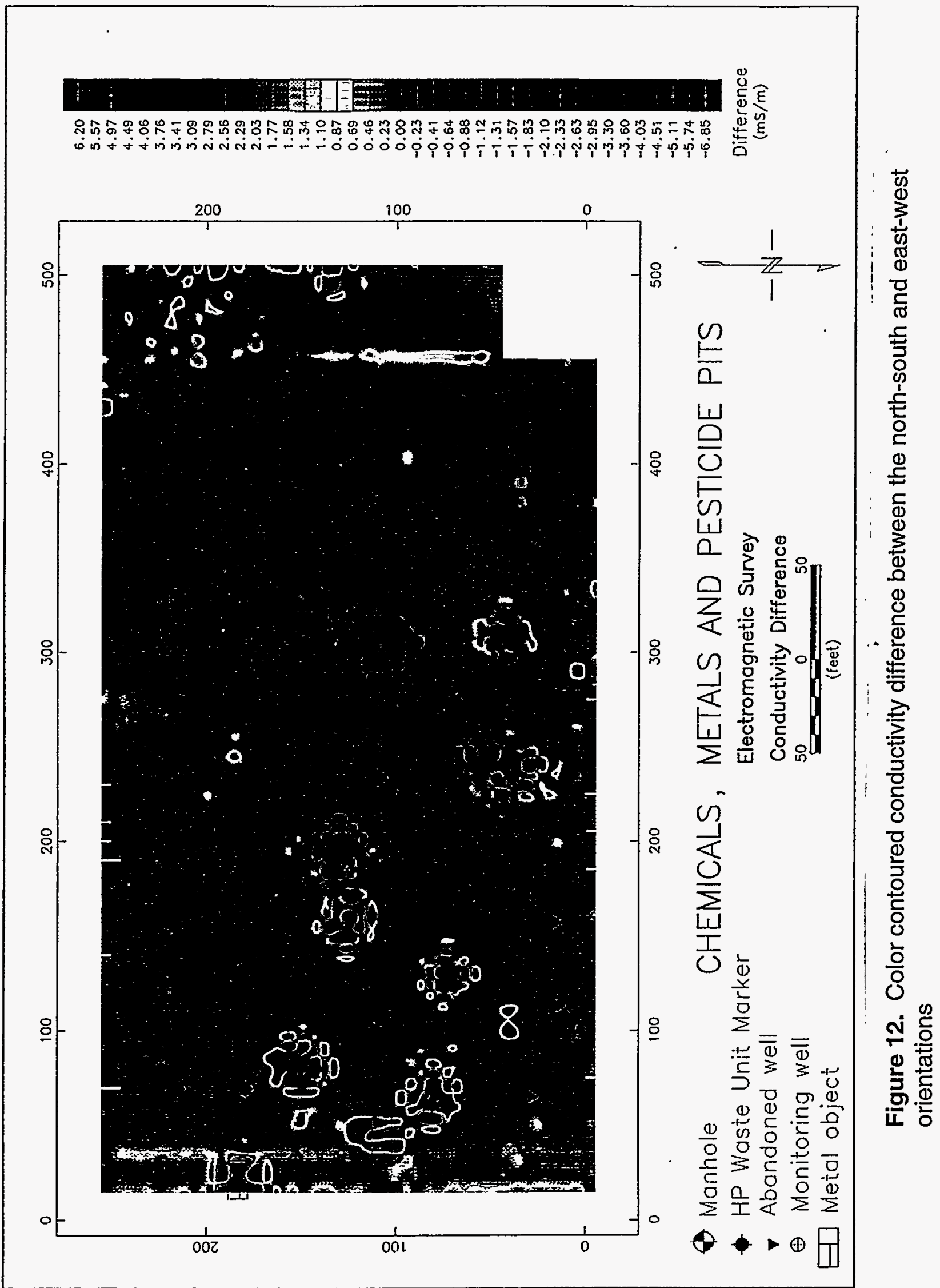




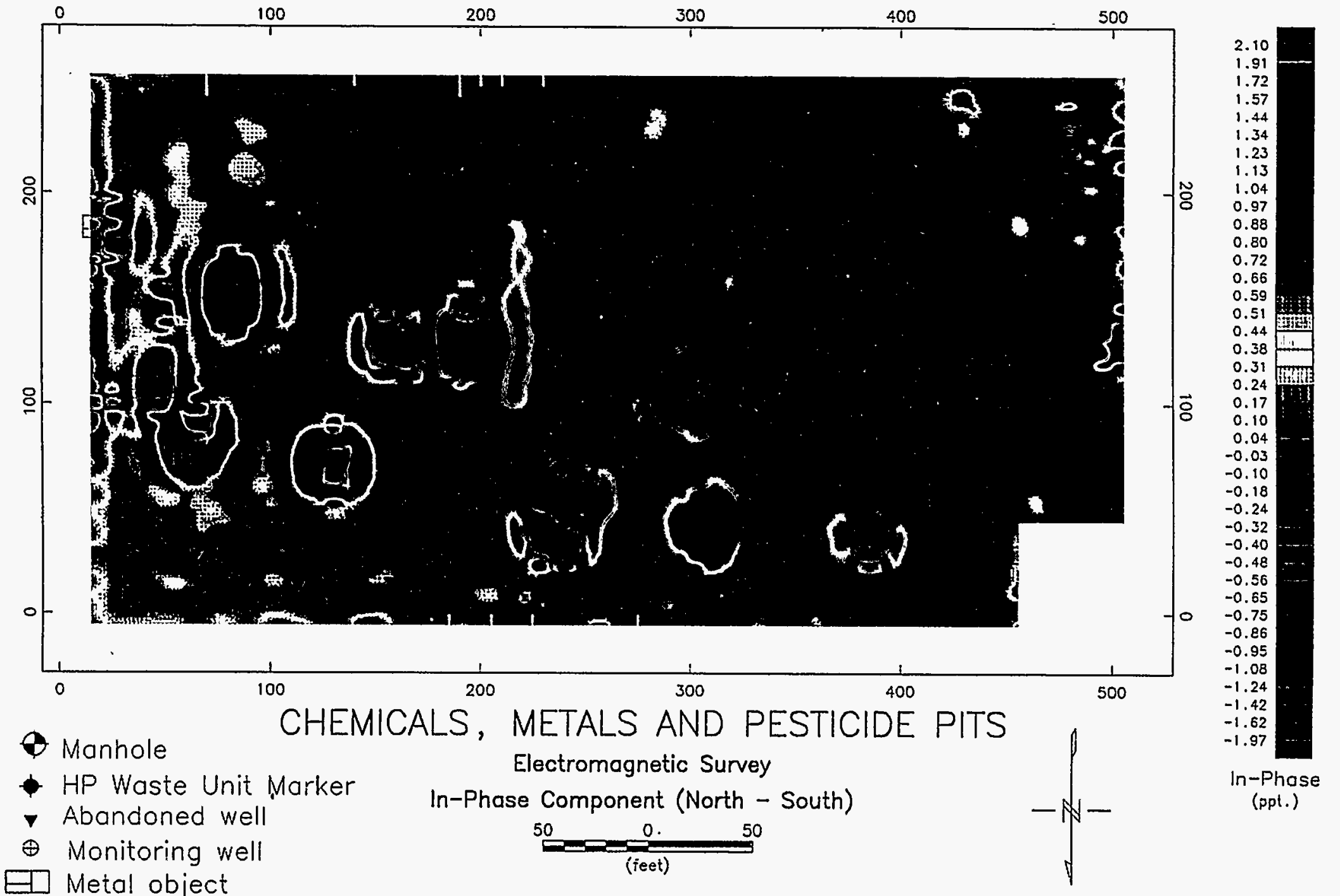

Figure 13. Color contoured vertical dipole in-phase component for north-south dipole common axis orientation 


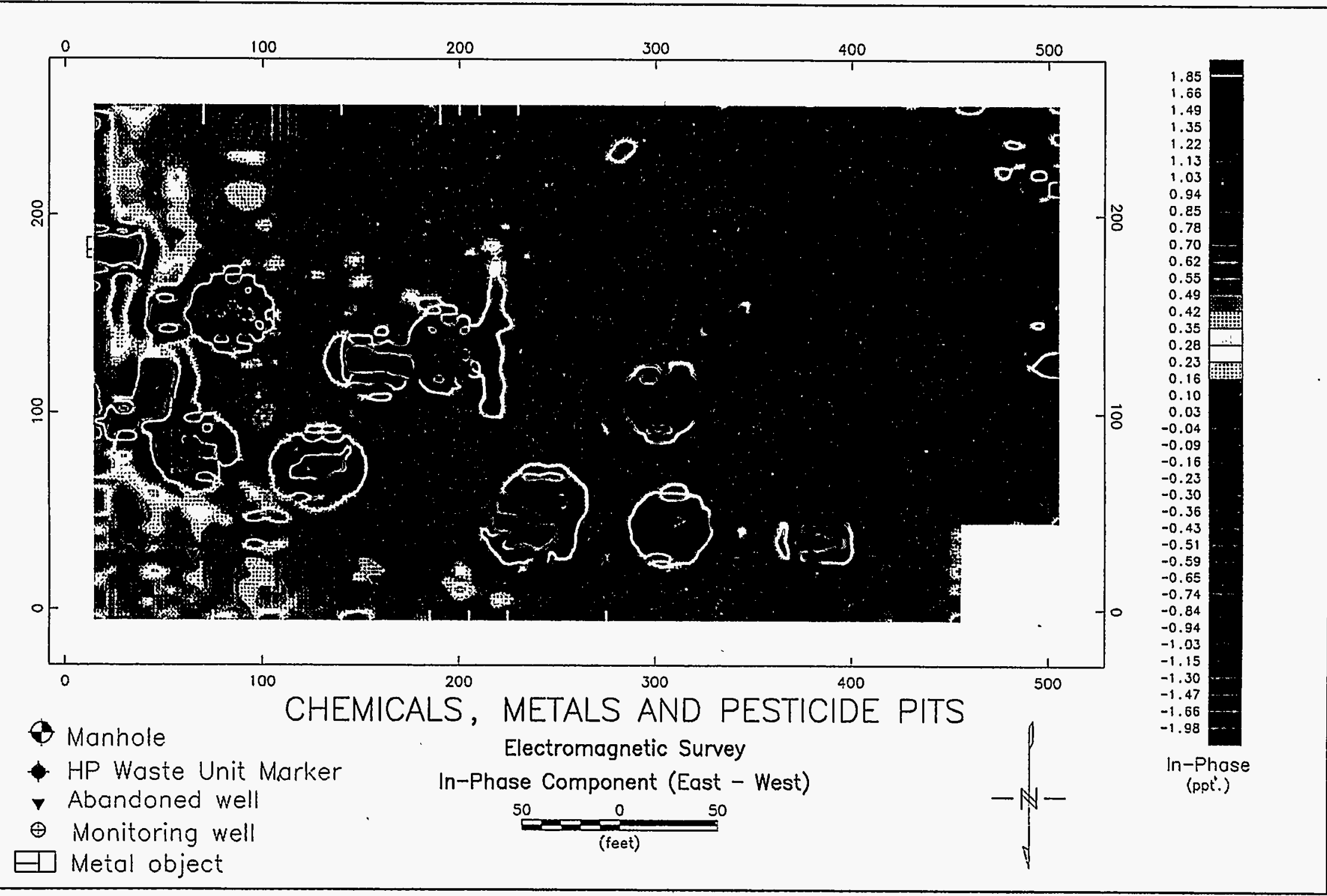

Figure 14. Color contoured vertical dipole in-phase component for east-west dipole common axis orientation 


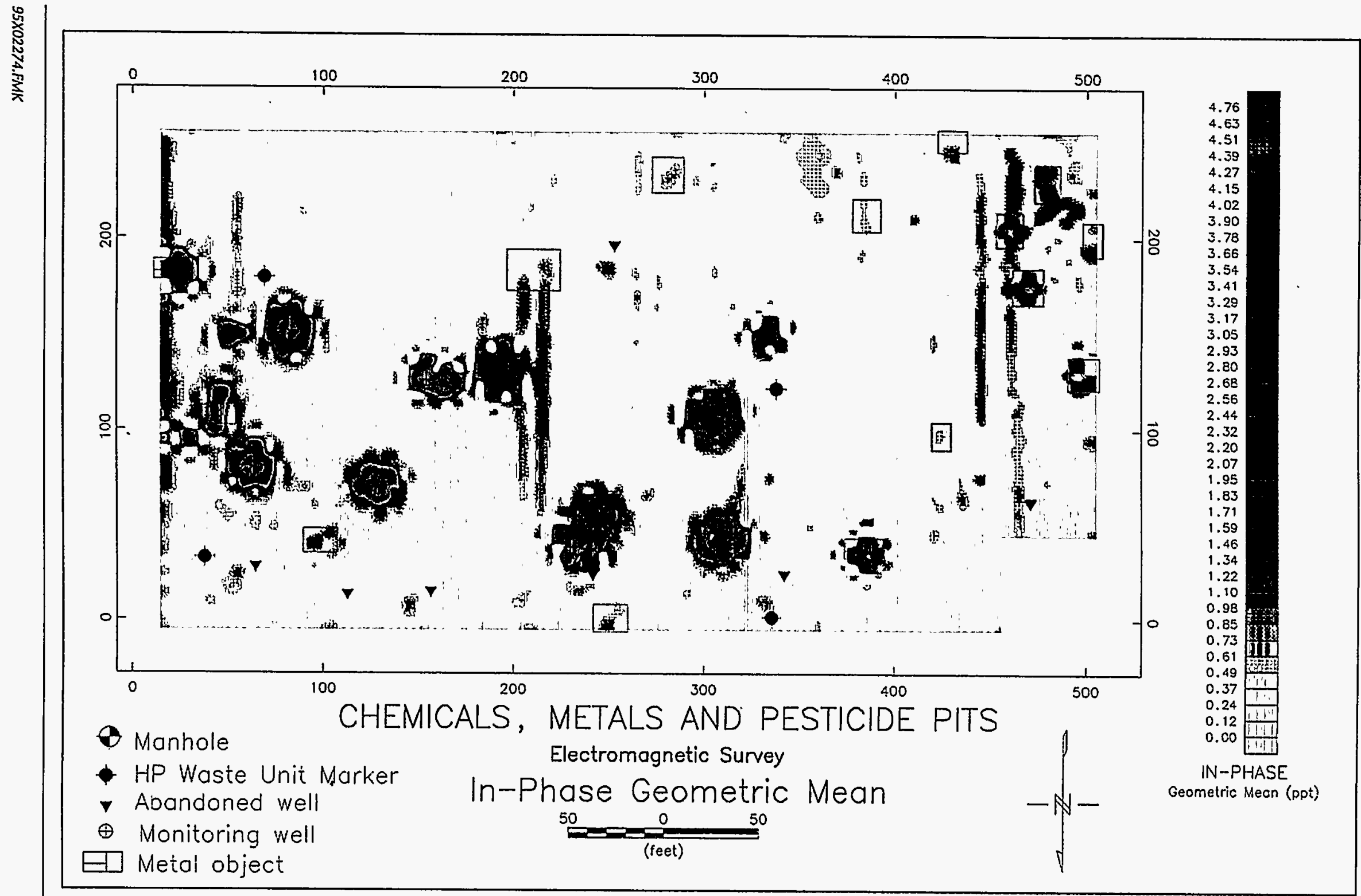

Figure 15. Color contoured geometric mean for both orientations of in-phase data with suspected areas of buried metallic objects outlined 
This page intentionally left blank. 


\section{Appendix A-Surveyed Electromagnetic Survey. Station Locations}


This page intentionally left blank. 


\begin{tabular}{|l|l|l|l|l|}
\hline Line & \multicolumn{3}{|c|}{ SITE } & GRID \\
\hline A-0 & 54055.20 & 51575.71 & 0 & 0 \\
A-1 & 54051.24 & 51578.76 & 5 & 0 \\
A-2 & 54047.28 & 51581.81 & 10 & 0 \\
A-3 & 54043.32 & 51584.87 & 15 & 0 \\
A-4 & 54039.36 & 51587.92 & 20 & 0 \\
A-5 & 54035.40 & 51590.97 & 25 & 0 \\
A-6 & 54031.44 & 51594.02 & 30 & 0 \\
A-7 & 54027.48 & 51597.07 & 35 & 0 \\
A-8 & 54023.52 & 51600.13 & 40 & 0 \\
A-9 & 54019.56 & 51603.18 & 45 & 0 \\
A-10 & 54015.60 & 51606.23 & 50 & 0 \\
A-11 & 54011.64 & 51609.28 & 55 & 0 \\
A-12 & 54007.68 & 51612.33 & 60 & 0 \\
A-13 & 54003.72 & 51615.39 & 65 & 0 \\
A-14 & 53999.75 & 51618.44 & 70 & 0 \\
A-15 & 53995.79 & 51621.49 & 75 & 0 \\
A-16 & 53991.83 & 51624.54 & 80 & 0 \\
A-17 & 53987.87 & 51627.59 & 85 & 0 \\
A-18 & 53983.91 & 51630.65 & 90 & 0 \\
A-19 & 53979.95 & 51633.70 & 95 & 0 \\
A-20 & 53975.99 & 51636.75 & 100 & 0 \\
A-21 & 53972.03 & 51639.80 & 105 & 0 \\
A-22 & 53968.07 & 51642.85 & 110 & 0 \\
A-23 & 53964.11 & 51645.91 & 115 & 0 \\
A-24 & 53960.15 & 51648.96 & 120 & 0 \\
A-25 & 53956.19 & 51652.01 & 125 & 0 \\
A-26 & 53952.23 & 51655.06 & 130 & 0 \\
A-27 & 53948.27 & 51658.11 & 135 & 0 \\
A-28 & 53944.31 & 51661.17 & 140 & 0 \\
A-29 & 53940.35 & 51664.22 & 145 & 0 \\
A-30 & 53936.39 & 51667.27 & 150 & 0 \\
A-31 & 53932.43 & 51670.32 & 155 & 0 \\
A-32 & 53928.47 & 51673.37 & 160 & 0 \\
A-33 & 53924.51 & 51676.43 & 165 & 0 \\
A-34 & 53920.55 & 51679.48 & 170 & 0 \\
A-35 & 53916.59 & 51682.53 & 175 & 0 \\
A-36 & 53912.62 & 51685.58 & 180 & 0 \\
A-37 & 53908.66 & 51688.63 & 185 & 0 \\
A-38 & 53904.70 & 51691.69 & 190 & 0 \\
A-39 & 53900.74 & 51694.74 & 195 & 0 \\
A-40 & 53896.78 & 51697.79 & 200 & 0 \\
A-41 & 53892.82 & 51700.84 & 205 & 0 \\
A-42 & 53888.86 & 51703.89 & 210 & 0 \\
A-43 & 53884.90 & 51706.95 & 215 & 0 \\
& 53880.94 & 51710.00 & 220 & 0 \\
& 53873.02 & 51716.10 & 230 & 0 \\
\hline
\end{tabular}

\begin{tabular}{|c|c|c|c|c|}
\hline \multirow[b]{2}{*}{ Line } & \multicolumn{2}{|c|}{ SITE } & \multicolumn{2}{|c|}{ GRID } \\
\hline & Easting & INorthing & $x$ & $\mathbf{Y}$ \\
\hline$\overline{D-0}$ & 53963.64 & 51456.90 & 0 & 150 \\
\hline$D-1$ & 53959.68 & 51459.95 & 5 & 150 \\
\hline D-2 & 53955.72 & 51463.00 & 10 & 150 \\
\hline D-3 & 53951.76 & 51466.05 & 15 & 150 \\
\hline$D-4$ & 53947.80 & 51469.10 & 20 & 150 \\
\hline D-5 & 53943.84 & 51472.16 & 25 & 150 \\
\hline D-6. & 53939.88 & 51475.21 & 30 & 150 \\
\hline D-7 & 53935.92 & 51478.26 & 35 & 150 \\
\hline D-8 & 53931.96 & 51481.31 & 40 & 150 \\
\hline D-9 & 53928.00 & 51484.36 & 45 & 150 \\
\hline$D-10$ & 53924.04 & 51487.42 & 50 & 150 \\
\hline D-11 & 53920.08 & 51490.47 & 55 & 150 \\
\hline$D-12$ & 53916.12 & 51493.52 & 60 & 150 \\
\hline$D-13$ & 53912.16 & 51496.57 & 65 & 150 \\
\hline D-14 & 53908.19 & 51499.62 & 70 & 150 \\
\hline D-15 & 53904.23 & 51502.68 & 75 & 150 \\
\hline$D-16$ & 53900.27 & 51505.73 & 80 & 150 \\
\hline D-17 & 53896.31 & 51508.78 & 85 & 150 \\
\hline$D-18$ & 53892.35 & 51511.83 & 90 & 150 \\
\hline D-19 & 53888.39 & 51514.88 & 95 & 150 \\
\hline$D-20$ & 53884.43 & 51517.94 & 100 & 150 \\
\hline D-21 & 53880.47 & 51520.99 & 105 & 150 \\
\hline$D-22$ & 53876.51 & 51524.04 & 110 & 150 \\
\hline D-23 & 53872.55 & 51527.09 & 115 & 150 \\
\hline D-24 & 53868.59 & 51530.14 & 120 & 150 \\
\hline D-25 & 53864.63 & 51533.20 & 125 & 150 \\
\hline D-26 & 53860.67 & 51536.25 & 130 & 150 \\
\hline D-27 & 53856.71 & 51539.30 & 135 & 150 \\
\hline$D-28$ & 53852.75 & 51542.35 & 140 & 150 \\
\hline$D-29$ & 53848.79 & 51545.40 & 145 & 150 \\
\hline D-30 & 53844.83 & 51548.46 & 150 & 150 \\
\hline$D-31$ & 53840.87 & 51551.51 & 155 & 150 \\
\hline D-32 & 53836.91 & 51554.56 & 160 & 150 \\
\hline$D-33$ & 53832.95 & 51557.61 & 165 & 150 \\
\hline$D-34$ & 53828.99 & 51560.66 & 170 & 150 \\
\hline D-35 & 53825.02 & 51563.72 & 175 & 150 \\
\hline D-36 & 53821.06 & 51566.77 & 180 & 150 \\
\hline D-37 & 53817.10 & 51569.82 & 185 & 150 \\
\hline D-38 & 53813.14 & 51572.87 & 190 & 150 \\
\hline D-39 & 53809.18 & 51575.92 & 195 & 150 \\
\hline$D-40$ & 53805.22 & 51578.98 & 200 & 150 \\
\hline$D-41$ & 53801.26 & 51582.03 & 205 & 150 \\
\hline D-42 & 53797.30 & 51585.08 & 210 & 150 \\
\hline$D-43$ & 53793.34 & 51588.13 & 215 & 150 \\
\hline D-44 & 53789.38 & 51591.18 & 220 & 150 \\
\hline$D-45$ & 53785.42 & 51594.24 & 225 & 150 \\
\hline D-46 & 53781.46 & 51597.29 & 230 & 150 \\
\hline
\end{tabular}




\begin{tabular}{|c|c|c|c|c|}
\hline & \multicolumn{3}{|c|}{ SITE } & \multicolumn{2}{|c|}{ GRID } \\
Line & Easting & Northing & X & $Y$ \\
\hline A-47 & 53869.06 & 51719.15 & 235 & 0 \\
A-48 & 53865.10 & 51722.21 & 240 & 0 \\
A-49 & 53861.14 & 51725.26 & 245 & 0 \\
A-50 & 53857.18 & 51728.31 & 250 & 0 \\
A-51 & 53853.22 & 51731.36 & 255 & 0 \\
A-52 & 53849.26 & 51734.41 & 260 & 0 \\
A-53 & 53845.30 & 51737.47 & 265 & 0 \\
A-54 & 53841.34 & 51740.52 & 270 & 0 \\
A-55 & 53837.38 & 51743.57 & 275 & 0 \\
A-56 & 53833.42 & 51746.62 & 280 & 0 \\
A-57 & 53829.45 & 51749.67 & 285 & 0 \\
A-58 & 53825.49 & 51752.73 & 290 & 0 \\
A-59 & 53821.53 & 51755.78 & 295 & 0 \\
A-60 & 53817.57 & 51758.83 & 300 & 0 \\
A-61 & 53813.61 & 51761.88 & 305 & 0 \\
A-62 & 53809.65 & 51764.93 & 310 & 0 \\
A-63 & 53805.69 & 51767.99 & 315 & 0 \\
A-64 & 53801.73 & 51771.04 & 320 & 0 \\
A-65 & 53797.77 & 51774.09 & 325 & 0 \\
A-66 & 53793.81 & 51777.14 & 330 & 0 \\
A-67 & 53789.85 & 51780.19 & 335 & 0 \\
A-68 & 53785.89 & 51783.25 & 340 & 0 \\
A-69 & 53781.93 & 51786.30 & 345 & 0 \\
A-70 & 53777.97 & 51789.35 & 350 & 0 \\
A-71 & 53774.01 & 51792.40 & 355 & 0 \\
A-72 & 53770.05 & 51795.45 & 360 & 0 \\
A-73 & 53766.09 & 51798.51 & 365 & 0 \\
A-74 & 53762.13 & 51801.56 & 370 & 0 \\
A-75 & 53758.17 & 51804.61 & 375 & 0 \\
A-76 & 53754.21 & 51807.66 & 380 & 0 \\
A-77 & 53750.25 & 51810.71 & 385 & 0 \\
A-78 & 53746.29 & 51813.77 & 390 & 0 \\
A-79 & 53742.32 & 51816.82 & 395 & 0 \\
A-80 & 53738.36 & 51819.87 & 400 & 0 \\
A-81 & 53734.40 & 51822.92 & 405 & 0 \\
A-82 & 53730.44 & 51825.97 & 410 & 0 \\
A-83 & 53726.48 & 51829.03 & 415 & 0 \\
A-84 & 53722.52 & 51832.08 & 420 & 0 \\
A-85 & 53718.56 & 51835.13 & 425 & 0 \\
A-86 & 53714.60 & 51838.18 & 430 & 0 \\
A-87 & 53710.64 & 51841.23 & 435 & 0 \\
A-88 & 53706.68 & 51844.29 & 440 & 0 \\
A-89 & 53702.72 & 51847.34 & 445 & 0 \\
A-90 & 53698.76 & 51850.39 & 450 & 0 \\
B-0 & 54024.68 & 51536.10 & 0 & 50 \\
B-1 & 54020.72 & 51539.16 & 5 & 50 \\
B-2 & 54016.76 & 51542.21 & 10 & 50 \\
B-3 & 54012.80 & 51545.26 & 15 & 50 \\
B-4 & 54008.84 & 51548.31 & 20 & 50 \\
- & & & & \\
\hline
\end{tabular}

\begin{tabular}{|c|c|c|c|c|}
\hline & & & & \\
\hline & asting & & $\mathbf{x}$ & \\
\hline D-47 & 53777.50 & 51600.34 & 235 & 150 \\
\hline 48 & 53773.54 & 51603.39 & 240 & 150 \\
\hline 49 & 53769.58 & 51606.44 & 245 & 150 \\
\hline .50 & 53765.62 & 51609.50 & 250 & 150 \\
\hline 51 & 53761.66 & 51612.55 & 255 & 150 \\
\hline 52 & 53757.70 & 51615.60 & 260 & 150 \\
\hline 53 & 53753.74 & 5.1618 .65 & 265 & 150 \\
\hline 54 & 53749.78 & 51621.70 & 270 & 150 \\
\hline 55 & 53745.82 & 51624.76 & 275 & 150 \\
\hline D-56 & 53741.86 & 51627.81 & 280 & 150 \\
\hline D-57 & 53737.89 & 51630.86 & 285 & 150 \\
\hline 58 & 53733.93 & 51633.91 & 290 & 150 \\
\hline-59 & 53729.97 & 51636.96 & 295 & 150 \\
\hline-60 & 53726.01 & 51640.02 & 300 & 150 \\
\hline-61 & 53722.05 & 51643.07 & 305 & 150 \\
\hline-62 & 53718.09 & 51646.12 & 310 & 150 \\
\hline-63 & 53714.13 & 51649.17 & 315 & 10 \\
\hline 64 & 53710.17 & 51652.22 & 320 & 110 \\
\hline 65 & 53706.21 & 5165 & 325 & 150 \\
\hline 66 & 53702.25 & 516 & 330 & 15 \\
\hline 67 & 53698.29 & 516 & 335 & 15 \\
\hline 68 & 53694.33 & 516 & 340 & 15 \\
\hline 69 & 0.37 & 516 & 345 & 15 \\
\hline 70 & 536 & 516 & 350 & 15 \\
\hline 71 & 53682.45 & 516 & 355 & 150 \\
\hline 72 & 536 & 516 & 360 & \\
\hline 73 & 536 & 69 & 365 & 50 \\
\hline .74 & 536 & .74 & 370 & \\
\hline .75 & 536 & 516 & 375 & \\
\hline D-76. & 53662.65 & 516 & 380 & 150 \\
\hline D-77 & 53658.69 & 516 & 385 & 150 \\
\hline D-78 & 53654.73 & 516 & 390 & 150 \\
\hline D-79 & 53650.76 & 516 & 395 & 15 \\
\hline D-80 & 53646.80 & 517.01 .06 & 400 & 15 \\
\hline D-81 & 53642.84 & 5170 & 405 & 15 \\
\hline D-82 & 53638.88 & 5170 & 410 & 15 \\
\hline D-83 & 53634.92 & 51710.21 & 415 & 15 \\
\hline 84 & 53630.96 & 517 & 420 & \\
\hline 85 & 53627.00 & 517 & 425 & \\
\hline 86 & 53623.04 & 517 & 430 & \\
\hline 87 & 5361 & 5172 & 435 & \\
\hline & & 51725.47 & 440 & \\
\hline & 16 & 517 & 445 & \\
\hline & 53607.20 & 51731.58 & 450 & \\
\hline & 53603.24 & 51734.63 & 455 & \\
\hline D-92 & 53599.28 & 51737.68 & 460 & 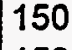 \\
\hline & 53595.32 & 51740.73 & 465 & 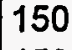 \\
\hline 84 & 53591.36 & 51743.78 & 470 & 10 \\
\hline 05 & 53587.40 & 51746.84 & 475 & \\
\hline
\end{tabular}




\begin{tabular}{|c|c|c|c|c|}
\hline \multirow[b]{2}{*}{ Line } & \multicolumn{2}{|c|}{ SITE } & \multicolumn{2}{|c|}{ GRID } \\
\hline & Easting & Northing & $\mathbf{x}$ & $Y$ \\
\hline B-5 & 54004.88 & 51551.36 & 25 & 50 \\
\hline B-6 & 54000.92 & 51554.42 & 30 & 50 \\
\hline B-7 & 53996.96 & 51557.47 & 35 & 50 \\
\hline B-8 & 53993.00 & 51560.52 & 40 & 50 \\
\hline B-9 & 53989.04 & 51563.57 & 45 & 50 \\
\hline-10 & 53985.08 & 51566.62 & 50 & 50 \\
\hline B-11 & 53981.12 & 51569.68 & 55 & 50 \\
\hline B-12 & 53977.16 & 51572.73 & 60 & 50 \\
\hline$B-13$ & 53973.20 & 51575.78 & 65 & 50 \\
\hline B-14 & 53969.23 & 51578.83 & 70 & 50 \\
\hline B-15 & 53965.27 & 51581.89 & 75 & 50 \\
\hline B-16 & 53961.31 & 51584.94 & 80 & 50 \\
\hline B-17 & 53957.35 & 51587.99 & 85 & 50 \\
\hline B-18 & 53953.39 & 51591.04 & 90 & 50 \\
\hline B-19 & 53949.43 & 51594.09 & 95 & 50 \\
\hline B-20 & 53945.47 & 51597.15 & 100 & 50 \\
\hline B-21 & 53941.51 & 51600.20 & 105 & 50 \\
\hline B-22 & 53937.55 & 51603.25 & 110 & 50 \\
\hline B-23 & 53933.59 & 51606.30 & 115 & 50 \\
\hline B-24 & 53929.63 & 51609.35 & 120 & 50 \\
\hline B-25 & 53925.67 & 51612.41 & 125 & 50 \\
\hline B-26 & 53921.71 & 51615.46 & 130 & 50 \\
\hline B-27 & 53917.75 & 51618.51 & 135 & 50 \\
\hline B-28 & 53913.79 & 51621.56 & 140 & 50 \\
\hline B-29 & 53909.83 & 51624.61 & 145 & 50 \\
\hline B-30 & 53905.87 & 51627.67 & 150 & 50 \\
\hline B-31 & 53901.91 & 51630.72 & 155 & 50 \\
\hline B-32 & 53897.95 & 51633.77 & 160 & 50 \\
\hline B-33 & 53893.99 & 51636.82 & 165 & 50 \\
\hline B-34 & 53890.03 & 51639.87 & 170 & 50 \\
\hline B-35 & 53886.07 & 51642.93 & 175 & 50 \\
\hline B-36 & 53882.10 & 51645.98 & 180 & 50 \\
\hline B-37 & 53878.14 & 51649.03 & 185 & 50 \\
\hline B-38 & 53874.18 & 51652.08 & 190 & 50 \\
\hline B-39 & 53870.22 & 51655.13 & 195 & 50 \\
\hline B-40 & 53866.26 & 51658.19 & 200 & 50 \\
\hline$B-41$ & 53862.30 & 51661.24 & 205 & 50 \\
\hline B-42 & 53858.34 & 51664.29 & 210 & 50 \\
\hline B-43 & 53854.38 & 51667.34 & 215 & 50 \\
\hline$B-44$ & 53850.42 & 51670.39 & 220 & .50 \\
\hline B-45 & 53846.46 & 51673.45 & 225 & 50 \\
\hline B-46 & 53842.50 & 51676.50 & 230 & 50 \\
\hline$B-47$ & 53838.54 & 51679.55 & 235 & 50 \\
\hline B-48 & 53834.58 & 51682.60 & 240 & 50 \\
\hline$B-49$ & 53830.62 & 51685.65 & 245 & 50 \\
\hline B-5 & 53826.66 & 51688.71 & 250 & 50 \\
\hline$B-51$ & 53822.70 & 51691.76 & 255 & 50 \\
\hline B-52 & 53818.74 & 51694.81 & 260 & 50 \\
\hline & 53814.78 & 51697.86 & $\angle 00$ & \\
\hline
\end{tabular}

\begin{tabular}{|c|c|c|c|c|}
\hline & \multicolumn{3}{|c|}{ SITE } & \multicolumn{3}{|c|}{ GRID } \\
Line & Easting & Northing & X & Y \\
\hline D-96 & 53583.44 & 51749.89 & 480 & 150 \\
D-97 & 53579.48 & 51752.94 & 485 & 150 \\
D-98 & 53575.52 & 51755.99 & 490 & 150 \\
D-99 & 53571.56 & 51759.04 & 495 & 150 \\
D-100 & 53567.59 & 51762.10 & 500 & 150 \\
E-0 & 53933.12 & 51417.29 & 0 & 200 \\
E-1 & 53929.16 & 51420.34 & 5 & 200 \\
E-2 & 53925.20 & 51423.40 & 10 & 200 \\
E-3 & 53921.24 & 51426.45 & 15 & 200 \\
E-4 & 53917.28 & 51429.50 & 20 & 200 \\
E-5 & 53913.32 & 51432.55 & 25 & 200 \\
E-6 & 53909.36 & 51435.60 & 30 & 200 \\
E-7 & 53905.40 & 51438.66 & 35 & 200 \\
E-8 & 53901.44 & 51441.71 & 40 & 200 \\
E-9 & 53897.48 & 51444.76 & 45 & 200 \\
E-10 & 53893.52 & 51447.81 & 50 & 200 \\
E-11 & 53889.56 & 51450.86 & 55 & 200 \\
E-12 & 53885.60 & 51453.92 & 60 & 200 \\
E-13 & 53881.64 & 51456.97 & 65 & 200 \\
E-14 & 53877.67 & 51460.02 & 70 & 200 \\
E-15 & 53873.71 & 51463.07 & 75 & 200 \\
E-16 & 53869.75 & 51466.12 & 80 & 200 \\
E-17 & 53865.79 & 51469.18 & 85 & 200 \\
E-18 & 53861.83 & 51472.23 & 90 & 200 \\
E-19 & 53857.87 & 51475.28 & 95 & 200 \\
E-20 & 53853.91 & 51478.33 & 100 & 200 \\
E-21 & 53849.95 & 51481.38 & 105 & 200 \\
E-22 & 53845.99 & 51484.44 & 110 & 200 \\
E-23 & 53842.03 & 51487.49 & 115 & 200 \\
E-24 & 53838.07 & 51490.54 & 120 & 200 \\
E-25 & 53834.11 & 51493.59 & 125 & 200 \\
E-26 & 53830.15 & 51496.64 & 130 & 200 \\
E-27 & 53826.19 & 51499.70 & 135 & 200 \\
E-28 & 53822.23 & 51502.75 & 140 & 200 \\
E-29 & 53818.27 & 51505.80 & 145 & 200 \\
E-30 & 53814.31 & 51508.85 & 150 & 200 \\
E-31 & 53810.35 & 51511.90 & 155 & 200 \\
E-32 & 53806.39 & 51514.96 & 160 & 200 \\
E-33 & 53802.43 & 51518.01 & 165 & 200 \\
E-34 & 53798.47 & 51521.06 & 170 & 200 \\
E-35 & 53794.50 & 51524.11 & 175 & 200 \\
E-36 & 53790.54 & 51527.16 & 180 & 200 \\
E-37 & 53786.58 & 51530.22 & 185 & 200 \\
E-38 & 53782.62 & 51533.27 & 190 & 200 \\
E-40 & 53778.66 & 51536.32 & 195 & 200 \\
\hline & 53774.70 & 51539.37 & 200 & 200 \\
\hline
\end{tabular}




\begin{tabular}{|c|c|c|c|c|}
\hline & & & & \\
\hline ne & asting & Nor & $\mathbf{x}$ & $\mathbf{Y}$ \\
\hline B-54 & 53810.82 & 51700.91 & 270 & 50 \\
\hline B-55 & 53806.86 & 51703.97 & 275 & 50 \\
\hline B-56 & 53802.90 & 51707.02 & 280 & 50 \\
\hline B-57 & 53798.93 & 51710.07 & 285 & 50 \\
\hline B-58 & 53794.97 & 51713.12 & 290 & 50 \\
\hline B-59 & 53791.01 & 51716.17 & 295 & 50 \\
\hline B-60 & 53787.05 & 51719.23 & 300 & 50 \\
\hline$B-61$ & 53783.09 & 51722.28 & 305 & 50 \\
\hline B-62 & 53779.13 & 51725.33 & 310 & 50 \\
\hline$B-63$ & 53775.17 & 51728.38 & 315 & 50 \\
\hline B-64 & 53771.21 & 51731.43 & 320 & 50 \\
\hline B-65 & 53767.25 & 51734.49 & 325 & 50 \\
\hline B-66 & 53763.29 & 51737.54 & 330 & 50 \\
\hline B-67 & 53759.33 & 51740.59 & 335 & 50 \\
\hline B-68 & 53755.37 & 51743.64 & 340 & .50 \\
\hline B-69 & 53751.41 & 51746.69 & 345 & 50 \\
\hline B-70 & 53747.45 & 51749.75 & 350 & 50 \\
\hline B-71 & 53743.49 & 51752.80 & 355 & 50 \\
\hline B-72 & 53739.53 & 51755.85 & 360 & 50 \\
\hline B-73 & 53735.57 & 51758.90 & 365 & 50 \\
\hline B-74 & 53731.61 & 51761.95 & 370 & 50 \\
\hline B-75 & 53727.65 & 51765.01 & 375 & 50 \\
\hline B-76 & 53723.69 & 51768.06 & 380 & 50 \\
\hline B-77 & 53719.73 & 51771.11 & 385 & 50 \\
\hline B-78 & 53715.77 & 51774.16 & 390 & 50 \\
\hline B-79 & 53711.80 & 51777.21 & 395 & 50 \\
\hline B-80 & 53707.84 & 51780.27 & 400 & 50 \\
\hline$B-81$ & 53703.88 & 51783.32 & 405 & 50 \\
\hline B-82 & 53699.92 & 51786.37 & 410 & 50 \\
\hline B-83 & 53695.96 & 51789.42 & 415 & 50 \\
\hline B-84 & 53692.00 & 51792.47 & 420 & 50 \\
\hline B-85 & 53688.04 & 51795.53 & 425 & 50 \\
\hline B-86 & 53684.08 & 51798.58 & 430 & 50 \\
\hline$B-87$ & 53680.12 & 51801.63 & 435 & 50 \\
\hline B-88 & 53676.16 & 51804.68 & 440 & 50 \\
\hline B-89 & 53672.20 & 51807.73 & 445 & 50 \\
\hline B-90 & 53668.24 & 51810.79 & 450 & 50 \\
\hline B-91 & 53664.28 & 51813.84 & 455 & 50 \\
\hline B-92 & 53660.32 & 51816.89 & 460 & 50 \\
\hline B-93 & 53656.36 & 51819.94 & 465 & 50 \\
\hline B-94 & $53652: 40$ & 51822.99 & 470 & 50 \\
\hline B-95 & 53648.44 & 51826.05 & 475 & 50 \\
\hline B-96 & 53644.48 & 51829.10 & 480 & 50 \\
\hline B-97 & 53640.52 & 51832.15 & 485 & 50 \\
\hline B-98 & 53636.56 & 51835.20 & 490 & 50 \\
\hline B-99 & 53632.60 & 51838.25 & 495 & 50 \\
\hline 100 & 53628.64 & 51841.31 & 500 & 50 \\
\hline 10 & 53624.67 & 51844.36 & 505 & 50 \\
\hline 102 & 53620.71 & 51847.4 & $D_{51}$ & \\
\hline
\end{tabular}

\begin{tabular}{|c|c|c|c|c|}
\hline & & \multicolumn{2}{|c|}{ GRID } \\
\hline & ing & & & \\
\hline$E-44$ & 53758.86 & 51551.58 & 220 & 200 \\
\hline 5 & 90 & .63 & 225 & 200 \\
\hline & 50.94 & 51557.68 & 230 & 20 \\
\hline 47 & 53746.98 & 51560.74 & 235 & \\
\hline 48 & 53743.02 & 51563.79 & 240 & 1200 \\
\hline-49 & 53739.06 & 515 & 245 & 120 \\
\hline E-50 & 53735.10 & 51569.89 & 250 & 200 \\
\hline E-51 & 53731.14 & 51572.94 & 255 & 200 \\
\hline$E-52$ & 53727.18 & 51576.00 & 260 & 20 \\
\hline E-53 & 53723.22 & 51579.05 & 265 & 20 \\
\hline E-54 & 53719.26 & 51582.10 & 270 & 20 \\
\hline E-55 & 5.30 & 5.15 & 275 & 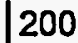 \\
\hline-56 & 1.34 & 3.20 & 280 & 1200 \\
\hline .57 & 7.37 & 51 & 285 & 1200 \\
\hline .58 & 3.41 & 51 & 290 & 1200 \\
\hline .59 & 9.45 & 51 & 295 & 201 \\
\hline 60 & 5.49 & 51 & 300 & 1200 \\
\hline 61 & .53691 .53 & $51 \epsilon$ & 305 & 20 \\
\hline E-62 & 53687.57 & 516 & 310 & 20 \\
\hline$E-63$ & 53683.61 & 516 & 315 & 0 \\
\hline$E-64$ & 53679.65 & $51 \epsilon$ & 320 & 200 \\
\hline$E-65$ & 53675.69 & 516 & 325 & 200 \\
\hline E-66 & 53671.73 & 51618.72 & 330 & 200 \\
\hline E-67 & 53667.77 & 51621.78 & 335 & 12 \\
\hline E-68 & 53663.81 & 51624.83 & 340 & 1.20 \\
\hline E-69 & 53659.85 & 51627.88 & 345 & 20 \\
\hline$E-70$ & 536 & 0.93 & 350 & 20 \\
\hline 71 & 1.93 & 51 & 355 & 20 \\
\hline$E-72$ & .97 & 516 & 360 & 20 \\
\hline E-73 & 53 & 51 & 365 & 20 \\
\hline E-74 & 53 & 51 & 370 & 20 \\
\hline$E-75$ & $53 \hat{\epsilon}$ & 516 & 375 & 20 \\
\hline E-76 & 536 & 51649.24 & 380 & 20 \\
\hline$E-77$ & 53628.17 & 51652.30 & 385 & 20 \\
\hline$E-78$ & 53624.21 & 51655.35 & 390 & 20 \\
\hline-79 & .53620 .24 & 51658.40 & 395 & \\
\hline$E-80$ & 536 & 516 & 400 & \\
\hline 81 & 536 & .50 & 405 & \\
\hline E-82 & 536 & 51 & 410 & \\
\hline E-83 & 536 & 51 & 415 & \\
\hline E-84 & 53600.44 & 51673.66 & 420 & 20 \\
\hline E-85 & 53596.48 & 51676.71 & 425 & 00 \\
\hline E-86 & 53592.52 & 51679.76 & 430 & 200 \\
\hline$E-87$ & 53588.56 & 51682.82 & 435 & 200 \\
\hline E-88 & 53584.60 & 51685.87 & 440 & 10 \\
\hline E-89 & 53580.64 & 51688.92 & 445 & \\
\hline 90 & 53576.68 & 51691.97 & 450 & \\
\hline & 53572.72 & 51695.02 & 455 & \\
\hline & & & & \\
\hline
\end{tabular}




\begin{tabular}{|c|c|c|c|c|}
\hline & & $\mathbf{T}$ & & \\
\hline Line & Easting & Northing & $\mathbf{x}$ & $Y$ \\
\hline C-O & 53994.16 & 51496.50 & 0 & 100 \\
\hline$C-1$ & 53990.20 & 51499.55 & 5 & 100 \\
\hline C-2 & 53986.24 & 51502.60 & 10 & 100 \\
\hline C-3 & 53982.28 & 51505.66 & 15 & 100 \\
\hline$C-4$ & 53978.32 & 51508.71 & 20 & 100 \\
\hline C-5 & 53974.36 & 51511.76 & 25 & 100 \\
\hline C-6 & 53970.40 & 51514.81 & 30 & 100 \\
\hline C-7 & 53966.44 & 51517.86 & 35 & 100 \\
\hline C-8 & 53962.48 & 51520.92 & 40 & 100 \\
\hline C-9 & 53958.52 & 51523.97 & 45 & 100 \\
\hline C-10 & 53954.56 & 51527.02 & 50 & 100 \\
\hline$C-11$ & 53950.60 & 51530.07 & 55 & 100 \\
\hline C-12 & 53946.64 & 51533.12 & 60 & 100 \\
\hline$C-13$ & 53942.68 & 51536.18 & 65 & 100 \\
\hline$C-14$ & 53938.71 & 51539.23 & 70 & 100 \\
\hline$C-15$ & 53934.75 & 51542.28 & 75 & 100 \\
\hline$C-16$ & 53930.79 & 51545.33 & 80 & 100 \\
\hline$C-17$ & 53926.83 & 51548.38 & 85 & 1.00 \\
\hline$C-18$ & 53922.87 & 51551.44 & 90 & 100 \\
\hline C-19 & 53918.91 & 51554.49 & 95 & 100 \\
\hline C-20 & 53914.95 & 51557.54 & 100 & 100 \\
\hline$C-20$ & 53910.99 & 51560.59 & 105 & 100 \\
\hline C-22 & 53907.03 & 51563.64 & 110 & 100 \\
\hline C-23 & 53903.07 & 51566.70 & 115 & 100 \\
\hline C-24 & 53899.11 & 51569.75 & 120 & 100 \\
\hline C-25 & 53895.15 & 51572.80 & 125 & 100 \\
\hline C-26 & 53891.19 & 51575.85 & 130 & 100 \\
\hline C-27 & 53887.23 & 51578.90 & 135 & 100 \\
\hline C-28 & 53883.27 & 51581.96 & 140 & 100 \\
\hline C-29 & 53879.31 & 51585.01 & 145 & 100 \\
\hline$C-30$ & 53875.35 & 51588.06 & 150 & 100 \\
\hline C-31 & 53871.39 & 51591.11 & 155 & 100 \\
\hline C-32 & 53867.43 & 51594.16 & 160 & 100 \\
\hline C-33 & 53863.47 & 51597.22 & 165 & 100 \\
\hline C-34 & 53859.51 & 51600.27 & 170 & 100 \\
\hline C-35 & 53855.55 & 51603.32 & 175 & 100 \\
\hline C-36 & 53851.58 & 51606.37 & 180 & 100 \\
\hline C-37 & 53847.62 & 51609.42 & 185 & 100 \\
\hline C-38 & 53843.66 & 51612.48 & 190 & 100 \\
\hline C-39 & 53839.70 & 51615.53 & 195 & 100 \\
\hline C- 40 & 53835.74 & 51618.58 & 200 & 100 \\
\hline$C-41$ & 53831.78 & 51621.63 & 205 & 10 \\
\hline C-42 & 53827.82 & 51624.68 & 210 & 100 \\
\hline $\mathrm{C}-43$ & 53823.86 & 51627.74 & 215 & 100 \\
\hline C-44 & 53819.90 & 51630.79 & 220 & 100 \\
\hline C-45 & 53815.94 & 51633.84 & 225 & 100 \\
\hline$C-46$ & 53811.98 & 51636.89 & 230 & 100 \\
\hline C-47 & 53808.02 & 51639.94 & 235 & 10 \\
\hline 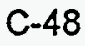 & 53804.0 & 51643 & $1<4$ & \\
\hline
\end{tabular}

\begin{tabular}{|c|c|c|c|c|}
\hline & & \multicolumn{2}{|c|}{ GRID } \\
\hline & sting & & $\mathbf{x}$ & $\mathbf{Y}$ \\
\hline$E-93$ & 53564.80 & 51701.13 & 465 & 200 \\
\hline 94 & 560.84 & 5170 & 470 & 200 \\
\hline 95 & 53556.88 & 51707.23 & 475 & 200 \\
\hline-96 & 53552.92 & 51710.28 & 480 & 200 \\
\hline$E-97$ & 53548.96 & 51713.34 & 485 & 200 \\
\hline$E-98$ & 5.00 & 517 & 490 & \\
\hline E-99 & 53541.04 & 517 & 495 & 20 \\
\hline 100 & 53537.07 & 517 & 500 & 20 \\
\hline & 3.11 & 54 & 505 & \\
\hline 02 & 53529.15 & 60 & 510 & $<0$ \\
\hline 03 & 53525.19 & & 515 & 20 \\
\hline 104 & 53521.23 & 51 & 520 & 20 \\
\hline 105 & 53517.27 & 51 & 525 & 200 \\
\hline 106 & 53513.31 & 517 & 530 & 200 \\
\hline 107 & 53509.35 & 517 & 535 & 200 \\
\hline 18 & 53505.39 & 517 & 540 & \\
\hline 109 & 53501.43 & 51 & 545 & \\
\hline 10 & 7.47 & & 50 & U \\
\hline 11 & .51 & & 555 & \\
\hline 12 & 3.55 & 51 & 560 & 20 \\
\hline 13 & 534 & 51 & 565 & 20 \\
\hline 114 & 53481,63 & & 570 & 20 \\
\hline 115 & 53477.67 & 51 & 575 & 200 \\
\hline$F-0$ & 53902.60 & & 0 & 50 \\
\hline$F-1$ & 53898.64 & .74 & & \\
\hline$F-2$ & 53894.68 & 51 & 10 & \\
\hline$F=3$ & 53890.72 & & 15 & \\
\hline$F-4$ & 53886.76 & 51 & 20 & 25 \\
\hline F-5 & 53882.80 & 51 & 25 & 25 \\
\hline F-6 & 53878.84 & 51 & 30 & 25 \\
\hline-7 & 53 & & 35 & 25 \\
\hline-8 & 53 & & 40 & 25 \\
\hline F-9 & 538 & & 45 & 25 \\
\hline$F-10$ & 53863.00 & & 50 & 250 \\
\hline$F-11$ & 53859.04 & & 55 & 250 \\
\hline$F-12$ & 53855.08 & .31 & 60 & 2 \\
\hline$F-13$ & 53851.11 & 51 & 65 & 2 \\
\hline$F-14$ & 53847.15 & .41 & 70 & 250 \\
\hline .15 & 53843.19 & .47 & 75 & $2 t$ \\
\hline 16 & 53839.23 & 51 & 80 & 25 \\
\hline & 53835.27 & & 85 & 2 \\
\hline & 53 & & 90 & 25 \\
\hline$F-19$ & 538 & .67 & 95 & 0 \\
\hline$F-20$ & 53823.39 & 514 & 100 & 250 \\
\hline$=-21$ & 538 & .78 & 105 & 250 \\
\hline$F-22$ & 53815.47 & 514 & 110 & 250 \\
\hline $1-<0$ & 53811.51 & 51447.88 & 115 & 250 \\
\hline & 53807.55 & 1.93 & 120 & \\
\hline & 53803 & 1453.99 & 12 & \\
\hline
\end{tabular}




\begin{tabular}{|c|c|c|c|c|}
\hline & & TF & & \\
\hline ne & Easting & Northing & $x$ & $\mathbf{Y}$ \\
\hline C-49 & 53800.10 & 51646.05 & 245 & 100 \\
\hline 50 & 53796.14 & 51649.10 & 250 & 100 \\
\hline .51 & 53792.18 & 51652.15 & 255 & 100 \\
\hline .52 & 53788.22 & 51655.20 & 260 & 100 \\
\hline .53 & 53784.26 & 51658.26 & 265 & 100 \\
\hline .54 & 53780.30 & 51661.31 & 270 & 100 \\
\hline .55 & 53776.34 & 51664.36 & 275 & 100 \\
\hline C-56 & 53772.38 & 51667.41 & 280 & 100 \\
\hline C-57. & 53768.41 & 51670.46 & 285 & 100 \\
\hline C-58 & 53764.45 & 51673.52 & 290 & 100 \\
\hline C-59 & 53760.49 & 51676.57 & 295 & 100 \\
\hline C-60 & 53756.53 & 51679.62 & 300 & 100 \\
\hline C-61 & 53752.57 & 51682.67 & 305 & 100 \\
\hline C-62 & 53748.61 & 51685.72 & 310 & 100 \\
\hline C-63 & 53744.65 & 51688.78 & 315 & 100 \\
\hline C-64 & 53740.69 & 51691.83 & 320 & 100 \\
\hline C-65 & 53736.73 & 51694.88 & 325 & 100 \\
\hline C-66 & 537.32 .77 & 51697.93 & 330 & 100 \\
\hline C-67 & 53728.81 & 51700.98 & 335 & 100 \\
\hline-68 & 53724.85 & 51704.04 & 340 & 100 \\
\hline$;-69$ & 53720.89 & .51707 .09 & 345 & 100 \\
\hline-70 & 53716.93 & 51710.14 & 350 & 100 \\
\hline-71 & 53712.97 & 51713.19 & 355 & 100 \\
\hline C-72 & 53709.01 & 51716.24 & 360 & 100 \\
\hline C-73 & 53705.05 & 51719.30 & 365 & 100 \\
\hline C-74 & 53701.09 & 51722.35 & 370 & 100 \\
\hline C-75 & 53697.13 & 51725.40 & 375 & 0 \\
\hline C-76 & 53693.17 & 51728.45 & 380 & 1.00 \\
\hline C-77 & 53689.21 & 51.731 .50 & 385 & 100 \\
\hline$c-78$ & 53685.25 & 51734.56 & 390 & 100 \\
\hline C-79 & 53681.28 & 51737.61 & 395 & 100 \\
\hline C.80 & 53677.32 & 51740.66 & 400 & 100 \\
\hline C-81 & 53673.36 & 51743.71 & 405 & 100 \\
\hline C-82 & 53669.40 & 51746.76 & 410 & 100 \\
\hline C-83' & 53665.44 & 51749.82 & 415 & 100 \\
\hline C-84 & 53661.48 & 51752.87 & 420 & 100 \\
\hline C-85 & 53657.52 & 51755.92 & 425 & 100 \\
\hline$C-86$ & 53653.56 & 51758.97 & 430 & 100 \\
\hline C-87 & 53649.60 & 51762.02 & 435 & 100 \\
\hline C-88 & 53645.64 & 51765.08 & 440 & 100 \\
\hline C-89 & 53641.68 & 51768.13 & 445 & 100 \\
\hline C-90 & 53637.72 & 51771.18 & 450 & 100 \\
\hline C-91 & 53633.76 & 51774.23 & 455 & 100 \\
\hline C-92 & 53629.80 & 51777.28 & 460 & 10 \\
\hline C-93 & 53625.84 & 51780.34 & 465 & 10 \\
\hline C-94 & 53621.88 & 51783.39 & 470 & 100 \\
\hline C-95 & 53617.92 & 51786.44 & 475 & 100 \\
\hline C-96 & 53613.96 & 51789.49 & 480 & 100 \\
\hline C-97 & 53610.00 & 51792.54 & 485 & 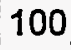 \\
\hline
\end{tabular}

\begin{tabular}{|c|c|c|c|c|}
\hline & & & & \\
\hline & sting & No & $\mathbf{x}$ & $\mathbf{Y}$ \\
\hline 26 & 3799.63 & 51457.04 & 130 & 250 \\
\hline & 795.67 & 514 & . & 250 \\
\hline & 53791.71 & 514 & 140 & 250 \\
\hline 29 & 53787.75 & 51466.19 & & 250 \\
\hline & 53783.79 & $514 E$ & 150 & 250 \\
\hline & .83 & 514 & & 250 \\
\hline 32 & 53775.87 & 51475.35 & 160 & 250 \\
\hline .33 & .91 & & 65 & 250 \\
\hline 34 & .95 & & 170 & 250 \\
\hline 35 & & & & 250 \\
\hline & & & 80 & 250 \\
\hline & & & 185 & 250 \\
\hline & & & 90 & 250 \\
\hline & & & 195 & 250 \\
\hline & & & 200 & 250 \\
\hline$\$ 1$ & & & 205 & 250 \\
\hline 42 & & & $210 \mid$ & 250 \\
\hline 43 & & & 215 & 250 \\
\hline & & & 220 & 250 \\
\hline & & & 225 & 250 \\
\hline & & & 230 & 250 \\
\hline & & & & 250 \\
\hline & & 51 & 240 & 250 \\
\hline & & & 245 & 250 \\
\hline 50 & & & 50 & 250 \\
\hline 51 & & & 55 & 250 \\
\hline & & & 60 & 250 \\
\hline & & & 265 & 250 \\
\hline & & & 270 & 250 \\
\hline & & & 275 & 250 \\
\hline & & & 280 & 50 \\
\hline & & & 285 & 250 \\
\hline & & & 290 & 250 \\
\hline & & & 295 & 250 \\
\hline & & & 00 & 250 \\
\hline & & & 05 & 250 \\
\hline & & & 310 & 250 \\
\hline & & & 315 & 250 \\
\hline & & & 20 & 250 \\
\hline & & & 25 & 250 \\
\hline & & & $330 \mid$ & 250 \\
\hline & & & 335 & 250 \\
\hline & & & 340 & 250 \\
\hline & & & 345 & 250 \\
\hline & & & 350 & 250 \\
\hline & & 51 & 355 & 50 \\
\hline & & & 360 & 50 \\
\hline & & & 365 & \\
\hline & & & & \\
\hline
\end{tabular}




\begin{tabular}{|c|c|c|c|c|}
\hline & \multicolumn{2}{|c|}{ SITE } & \multicolumn{2}{c|}{ GRID } \\
Line & Easting & Northing & $X$ & $Y$ \\
\hline C-98 & 53606.04 & 51795.60 & 490 & 100 \\
C-99 & 53602.08 & 51798.65 & 495 & 100 \\
C-100 & 53598.12 & 51801.70 & 500 & 100 \\
C-101 & 53594.15 & 51804.75 & 505 & 100 \\
C-102 & 53590.19 & 51807.80 & 510 & 100 \\
\hline
\end{tabular}

\begin{tabular}{|c|c|c|c|c|}
\hline & \multicolumn{3}{|c|}{ SITE } & \multicolumn{3}{c|}{ GRID } \\
Line & Easting & Northing & $X$ & $Y$ \\
\hline F-75 & 53605.57 & 51606.59 & 375 & 250 \\
F-76 & 53601.61 & 51609.64 & 380 & 250 \\
F-77 & 53597.65 & 51612.69 & 385 & 250 \\
F-78 & 53593.68 & 51615.74 & 390 & 250 \\
F-79 & 53589.72 & 51618.79 & 395 & 250 \\
F-80 & 53585.76 & 51621.85 & 400 & 250 \\
F-81 & 53581.80 & 51624.90 & 405 & 250 \\
F-82 & 53577.84 & 51627.95 & 410 & 250 \\
F-83 & 53573.88 & 51631.00 & 415 & 250 \\
F-84 & 53569.92 & 51634.05 & 420 & 250 \\
F-85 & 53565.96 & 51637.11 & 425 & 250 \\
F-86 & 53562.00 & 51640.16 & 430 & 250 \\
F-87 & 53558.04 & 51643.21 & 435 & 250 \\
F-88 & 53554.08 & 51646.26 & 440 & 250 \\
F-89 & 53550.12 & 51649.32 & 445 & 250 \\
F-90 & 53546.16 & 51652.37 & 450 & 250 \\
F-91 & 53542.20 & 51655.42 & 455 & 250 \\
F-92 & 53538.24 & 51658.47 & 460 & 250 \\
F-93 & 53534.28 & 51661.52 & 465 & 250 \\
F-94 & 53530.32 & 51664.58 & 470 & 250 \\
F-95 & 53526.36 & 51667.63 & 475 & 250 \\
F-96 & 53522.40 & 51670.68 & 480 & 250 \\
F-97 & 53518.44 & 51673.73 & 485 & 250 \\
F-98 & 53514.48 & 51676.78 & 490 & 250 \\
F-99 & 53510.52 & 51679.84 & 495 & 250 \\
F-100 & 53506.55 & 51682.89 & 500 & 250 \\
F-101 & 53502.59 & 51685.94 & 505 & 250 \\
F-102 & 53498.63 & 51688.99 & 510 & 250 \\
F-103 & 53494.67 & 51692.04 & 515 & 250 \\
F-104 & 53490.71 & 51695.10 & 520 & 250 \\
F-105 & 53486.75 & 51698.15 & 525 & 250 \\
\hline
\end{tabular}


This page intentionally left blank. 


\section{Appendix B-Instrument QA}


This page intentionally left blank. 


\begin{tabular}{|c|c|c|c|c|}
\hline meas.\# & $\begin{array}{c}\text { conductivity II } \\
\mathrm{mS} / \mathrm{m}\end{array}$ & $\begin{array}{l}\text { DA-phase } 11 \\
\text { ppt. }\end{array}$ & $\begin{array}{c}\text { conductivity }+ \\
\mathrm{ms} / \mathrm{m}^{-}\end{array}$ & $\begin{array}{c}\text { in-phase + } \\
\text { ppt. }\end{array}$ \\
\hline $\begin{array}{l}0 \\
1\end{array}$ & $\begin{array}{l}1.07 \\
1.16\end{array}$ & $\begin{array}{l}0.233 \\
0.193\end{array}$ & $\begin{array}{l}1.13 \\
143\end{array}$ & 0.222 \\
\hline $\begin{array}{l}7 \\
2\end{array}$ & $\begin{array}{l}1.16 \\
1.10\end{array}$ & $\begin{array}{l}0.193 \\
0.222\end{array}$ & 1.07 & 0.254 \\
\hline 3 & 0.98 & 0.198 & 1.19 & 0.220 \\
\hline 4 & 1.04 & 0.217 & 1.07 & 0.243 \\
\hline 5 & 1.04 & 0.226 & 1.25 & 0.233 \\
\hline 6 & 1.16 & 0.226 & 1.22 & 0.222 \\
\hline 7 & 1.01 & 0.220 & 1.13 & 0.244 \\
\hline 8 & 1.07 & 0.233 & 1.07 & 0.250 \\
\hline 9 & 0.95 & 0.259 & 1.04 & 0.246 \\
\hline mean: & 1.06 & 0.223 & 1.16 & 0.236 \\
\hline sd: & 0.07 & 0.019 & 0.12 & 0.013 \\
\hline
\end{tabular}

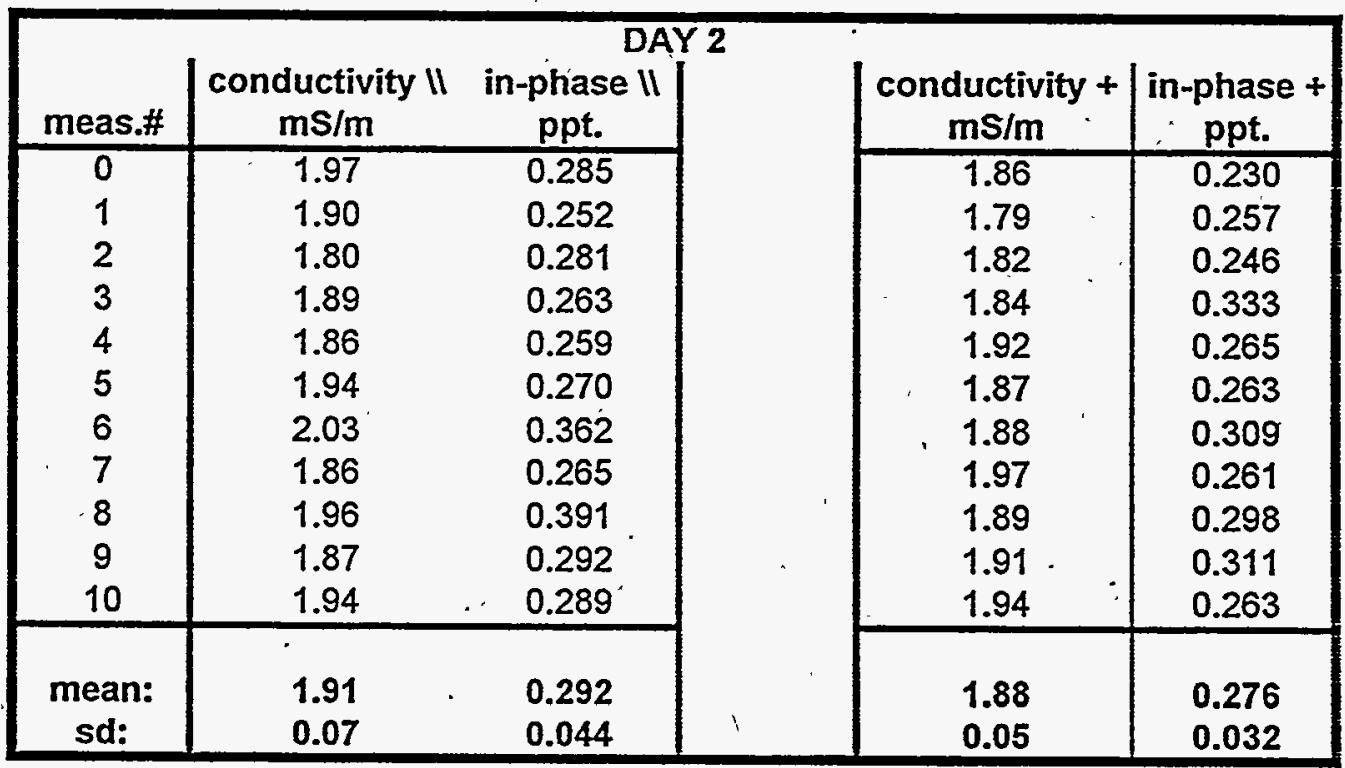


